Florida International University FIU Digital Commons

8-22-1994

\title{
Relationship between technical knowledge and price-perceived quality in an industrial setting
}

Jeannie Helen Caicedo

Florida International University

DOI: $10.25148 /$ etd.FI14052531

Follow this and additional works at: https://digitalcommons.fiu.edu/etd

Part of the Industrial Engineering Commons

\section{Recommended Citation}

Caicedo, Jeannie Helen, "Relationship between technical knowledge and price-perceived quality in an industrial setting" (1994). FIU Electronic Theses and Dissertations. 1967.

https://digitalcommons.fiu.edu/etd/1967 


\title{
FLORIDA INTERNATIONAL UNIVERSITY
}

\author{
Miami, Florida
}

RELATIONSHIP BETWEEN TECHNICAL KNOWLEDGE AND PRICE-PERCEIVED QUALITY IN AN INDUSTRIAL SETTING

A thesis submitted in partial satisfaction of the requirements for the degree of

MASTER OF SCIENCE

IN

INDUSTRIAL ENGINEERING

by

Jeannie Helen Caicedo 
To: Dean Gordon R. Hopkins

College of Engineering and Design

This thesis, written by Jeannie Helen Caicedo, and entitled RELATIONSHIP BETWEEN TECHNICAL KNOWLEDGE AND PRICE-PERCEIVED QUALITY IN AN INDUSTRIAL SETTING, having been approved in respect to style and intellectual content, is referred to you for judgement.

We have read this thesis and recommend that it be approved.

Shih-Ming Lee

Sergio Martinez

Marthá Aíxchel Centeno, Major Professor

Date of Defense: August 22, 1994

The thesis of Jeannie Helen Caicedo is approved.

Dean Gordon R. Hopḱins

College of Engineering and Design

Dr. Richard L. Campbell

Dean of Graduate Studies

Florida International University, 1994 
I dedicate this thesis to my family, to Dora Rodriguez, and to Guillermo Daw Alvarez. Without their patience, understanding, and encouragement, and most of all love, the completion of this thesis would not have been possible. I will like to make a special dedication to my baby sister, Christina, who was there for me when I really needed her support. Thanks, sis! 


\section{ACKNOWLEDGMENTS}

I wish to thank Dr. Shih-Ming Lee and Dr. Sergio Martinez, the members of my committee, for all their support and guidance. Even though I was working on my thesis all the way from Dalton, Georgia, they went extra miles to help me finish my thesis. I also want to thank: Nancy Urbina and Madlyn Calafell, for keeping me notified of all the requirements for graduation; Helida R. Fernandez, for helping me so kindly in the distribution of my surveys; and Zahir Rolling, for encouraging me when I needed it the most.

A very special thanks to my major professor, Dr. Martha Centeno, for all her support and expertise, and for having that extra energy in helping me complete my thesis. I feel very proud for having Dr. Centeno as my major professor because she really makes all the difference! 


\title{
ABSTRACT OF THE THESIS
}

\section{RELATIONSHIP BETWEEN TECHNICAL KNOWLEDGE}

\section{AND PRICE-PERCEIVED QUALITY IN AN INDUSTRIAL SETTING}

\author{
by \\ Jeannie Helen Caicedo \\ Florida International University, 1994 \\ Miami, Florida \\ Dr. Martha Aixchel Centeno, Major Professor
}

As proven by many studies, non-industrial consumers perceive price as a strong quality indicator. However, the applicability of this behavior to an industrial setting has been long questioned. It is hypothesized in this research that the levels of price-perceived quality will decrease in an industrial setting as the technical knowledge of the buyer increases. Judgement Sampling method was used to select the most appropriate sample for this study. Since engineers are particularly important influencers in the purchase decision process in organization, engineering students and professors were chosen as the study population. A survey was administered to a sample population that consisted of 153 respondents out of which $3.3 \%$ were professors, $9.8 \%$ graduate students, and $76.4 \%$ undergraduate students; $70.6 \%$ males and $15.7 \%$ females; $13.7 \%$ Mechanical Engineering, 28.1\% Industrial Engineering, 7.8\% Civil Engineering, 34\% Electrical Engineering, and 4.6\% Computer Engineering students. We evaluated the relationship between technical 
knowledge and price-perceived quality in an industrial setting using various regression models and other statistical models. Findings indicate that the price-perceived quality effect moves from an almost linear behavior to a nonlinear one as the technical knowledge increases. However, the transition from linear to nonlinear seems to be random. Further studies are needed. In our specific experiment, technical attributes, such as processing speed, RAM size, hard drive size, and CD-ROM speed, possess a strong positive relationship with quality (i.e. a "the faster, the better; the more, the merrier" type of situation); on other hand, our experiment indicates that price loses its significance as an indicator of quality as the buyer's technical knowledge increases. 
Dedication ................................. iii

Acknowledgments .......................... iv

Abstract .............................. v

List of Tables ........................... viii

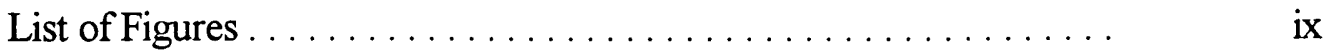

1. INTRODUCTION $\ldots \ldots \ldots \ldots \ldots \ldots \ldots \ldots \ldots \ldots \ldots \ldots \ldots$

1.1 Problem Statement . . . . . . . . . . . . . . . . . . . . . .

1.2 Objective of Study . . . . . . . . . . . . . . . . . . . . 7

1.3 Significance of Study . . . . . . . . . . . . . . . . . .

2. LITERATURE REVIEW . . . . . . . . . . . . . . . . . . . 11

3. RESEARCH METHODOLOGY $\ldots \ldots \ldots \ldots \ldots \ldots \ldots \ldots \ldots$

3.1 Study Population . . . . . . . . . . . . . . . . . . 18

3.2 Measurement Instrument and Procedures . . . . . . . . . . . . . . . 19

3.3 Analytical Techniques ....................... 23

4. RESEARCH FINDINGS $\ldots \ldots \ldots \ldots \ldots \ldots \ldots \ldots \ldots \ldots \ldots \ldots$

4.1 Background Information of Respondents . . . . . . . . . . . 28

4.2 Tier 1: Technical Scores . . . . . . . . . . . . . . . . . 30

4.3 Tier 2: Price-Perceived Quality Effect .............. 32

4.3.1 Attribute Ranking ................... 32

4.3.2 Semantic Differential Scale . . . . . . . . . . . . . . . . 37

4.3.3 Perceived Quality ...................... 39

4.3.4 Linear Regression...................... $\quad 39$

4.3.5 Graphical Assessment of Technical Knowledge ....... $\quad 45$

4.3.6 Pearson Product Moment Correlation Coefficient ...... 53

5. CONCLUSIONS AND FURTHER RESEARCH $\ldots \ldots \ldots \ldots \ldots \ldots$

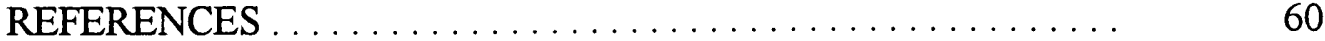

APPENDICES ........................... 67 


\section{LIST OF TABLES}

PAGE

1-1 Four Types of Buying Behavior $\ldots \ldots \ldots \ldots \ldots \ldots \ldots \ldots \ldots \ldots$

1-2 Consumer and Industrial Buying Processess . . . . . . . . . . . . 4

3-1 Computer Model Descriptions . . . . . . . . . . . . . . . . . 21

4-1 Level of Education . . . . . . . . . . . . . . . . . . . 29

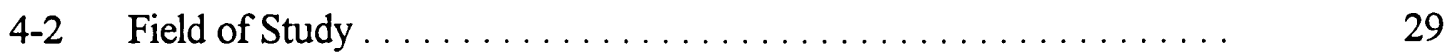

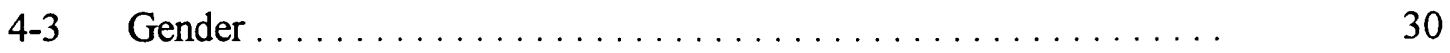

4-4 Engineering Classes Surveyed $\ldots \ldots \ldots \ldots \ldots \ldots \ldots \ldots \ldots \ldots$

4-5 Attribute Ranking Frequency and Statistics . . . . . . . . . . . 33

4-6 Semantic Differential Scale Statistics . . . . . . . . . . . . . . . 37

4-7 Computer Models: Rankings . . . . . . . . . . . . . . . . . . . . . . 39

4-8 Perceived Quality Regression Model . . . . . . . . . . . . . . . 40

4-9 Results of Hypotheses Test on Price Coefficient (Simple Regression) . . . 41

4-10 Technical Knowledge Regression Model Statistics ............ 42

4-11 Results of Hypotheses Test on the Regression Model ............ . 43

4-12 Results of Hypotheses Test on Price Coefficient (Multiple Regression) . . 44

4-13 Results of Hypotheses Test on Technical Knowledge Coefficient ...... 45

4-14 Mean Quality Rating per Knowledge Level ................ 46

4-15 Technical Attributes Correlated with Perceived Quality ........... 53 


\section{LIST OF FIGURES}

PAGE

4-1 Relative Frequency Histogram for $n=106$ Scores . . . . . . . . . 31

4-2 Technical Attribute Ranking Frequency (Part 1) ............ 34

4-3 Technical Attribute Ranking Frequency (Part 2) ............ 35

4-4 Average Quality Attribute Ranking ................ 36

4-5 Semantic Differential Scale ..................... 38

4-6a Level of Technical Knowledge and Price-Perceived Quality Effect .... . 47

4-6b Level of Technical Knowledge and Price-Perceived Quality Effect (3D). $\quad 47$

4-7 Price-Perceived Quality Pattern based on Technical Knowledge ....... 52

4-8 Technical Knowledge vs. Perceived Quality ............... 52 


\section{CHAPTER 1: INTRODUCTION}

Any person at the end of the consumption process is considered a buyer; according to Walters and Bergiel (1989), these buyers can be identified by the type of market to which they belong, namely the consumer and organizational markets.

The consumer market consists of all the individuals that buy and acquire goods and services for personal consumption. Henry Assael (1987) distinguished four types of consumer buying behavior based on the degree of buyer involvement in the purchase decision and the degree of differences among brands. According to Kotler (1988), and based on the work done by Assael (Table 1-1), depending on the level of involvement, the dollar value of the purchase, and the risk level of the purchase, the consumer may present a complex buying behavior, dissonance-reducing buying behavior, variety seeking buying behavior, or habitual seeking buying behavior. The consumer will show, for instance, habitual buying behavior, when products bought require low consumer involvement and there are a few differences between brands, whereas s/he will show complex buying behavior when products bought require high consumer involvement and there are significant brand differences. In addition, Kotler (1988) affirms that there is evidence that consumers have low involvement with most low-cost, frequently purchased products (habitual buying behavior), whereas consumers have high involvement with expensive, infrequently purchased and risky products. 
Table 1-1 Four Types of Buying Behavior (Assael, 1987)

\begin{tabular}{|l|l|l|}
\hline & High Involvement & Low Involvement \\
\hline $\begin{array}{l}\text { Significant Differences } \\
\text { Between Brands }\end{array}$ & $\begin{array}{l}\text { Complex } \\
\text { Buying Behavior }\end{array}$ & $\begin{array}{l}\text { Variety-Seeking } \\
\text { Buying Behavior }\end{array}$ \\
\hline $\begin{array}{l}\text { Few Differences } \\
\text { Between Brands }\end{array}$ & $\begin{array}{l}\text { Dissonance - Reducing } \\
\text { Buying Behavior }\end{array}$ & $\begin{array}{l}\text { Habitual } \\
\text { Buying Behavior }\end{array}$ \\
\hline
\end{tabular}

According to Kotler (1988), the organizational market is one of reseller markets, government markets, and industrial markets. Resellers buy goods and services to later resell them at a profit. Government agencies buy goods and services to carry out mandated governmental functions. Industrial buyers purchase products to meet organizational objectives; for example, they buy computer chips which are to be used in populating computer boards. In other words, the product bought by industrial buyers either 1) it becomes part of the finished product that is sold, 2) it is consumed in the production of the finished products, or 3) it is used to facilitate the selling of other products or services.

Since most research on buying behavior has been traditionally directed towards the consumer market, it is now time to redirect some of these efforts to the industrial buying behavior in order to discover similarities or differences between the two markets. Maybe some consumer marketing strategies can be applied to the industrial markets or modified to fit the behavior of industrial markets. Thorough knowledge of industrial buyer behavior would enable companies to develop cost-effective marketing strategies. Therefore, this study focused on how the price-perceived quality effect in consumer marketing is moderated by technical knowledge in an industrial setting. 
The thesis is laid out as follows: Chapter 2 reviews the relevant literature for this research, Chapter 3 presents the research methodology that was used to conduct this study, Chapter 4 discusses the research findings, and Chapter 5 summarizes our conclusions and points out directions for further research.

\subsection{PROBLEM STATEMENT}

Robinson, et. al. (1967) distinguished three types of industrial buying situations: a) straight rebuy, b) modified rebuy, and c) new task. The straight rebuy depicts a buying situation where the purchasing department orders on a routine basis (e.g. office supplies, bulk chemicals). Modified rebuy characterizes a situation where the buyer wants to modify product specifications, prices, delivery requirements, or other terms. The new task faces a purchaser with buying a product or service for the first time. The greater the cost and/or risk, the larger the number of decision participants are involved; the greater the information seeking, the longer the time to decide are needed.

Table 1-2 compares the major stages of the Consumer Buying Process and the Industrial Buying Process in relation to major buying situations (Kotler, 1988). The commonalities of these two processes does not transcend to the actual environments where they take place. 
Table 1-2 Consumer and Industrial Buying Processes

\begin{tabular}{|l|l|l|}
\hline Stages & Consumer Buying Process & Industrial Buying Process \\
\hline 1 & Problem recognition & Problem recognition \\
\hline 2 & Information search & General need description \\
\hline 3 & Evaluation of alternatives & Product specification \\
\hline 4 & Purchase Decision & Supplier's search \\
\hline 5 & Postpurchase behavior & Proposal solicitation \\
\hline 6 & & Supplier selection \\
\hline 7 & & Order-routine specification \\
\hline 8 & & Performance review \\
\hline
\end{tabular}

Specifically, industrial markets have the following characteristics that contrast sharply with consumer markets (Kotler, 1988).

1. Fewer Buyers: The industrial market normally deals with far few buyers than the consumer market.

2. Bigger Purchases: Many industrial markets are characterized from a high buy concentration ratio; i.e., a few large buyers account for most of the purchasing.

3. Close Supplier-Customer Relationship: Because of the smaller customer base and the importance and power of the larger customers over the suppliers, there is a close relationship between customers and sellers in industrial markets.

4. Geographically Concentrated Buyers: More than half of the nations industrial buyers are concentrated in seven states: New York, California, Pennsylvania, Illinois, Ohio, New Jersey, and Michigan.

5. Derived Demand: The demand for industrial goods is determined from the demand of consumer goods. If the demand for consumer goods weakens, so will the demand for all 
industrial goods entering into production.

6. Inelastic Demand: The total demand of most industrial products and services is not much affected by the price changes. Demand is especially inelastic in the short run because producers usually cannot make changes in their production methods in short periods of time.

7. Fluctuating Demand: The demand for industrial goods and services tend to be more volatile than the demand for consumer goods and services. A given percentage increase in consumer demand can lead to a more larger percentage increase in the demand for equipment necessary to produce the additional output.

8. Professional Purchasing: Professionally trained purchasing agents spend their careers learning how to buy better. They have a professional approach and a better ability to understand technical details leading to a more rational buying decision. This means that industrial marketers have to provide a greater amount of specific performance and technical data about their product.

9. Several Buying Influence: Typically, more people influence industrial buying decisions than consumer buying decisions. Buying committees consisting of technical experts are common in the purchase of major goods.

10. Decision Satisfaction: An organizational decision must satisfy the differing needs and objectives of a variety of participants from different operating functions and organizational levels (Moriarty, 1983). 
11. Buying Information: According to Moriarty (1983), certain types of organizational buying information, such as proposals, requests for quotations, or purchase contracts, add to an organizational purchase. This is a formal dimension normally not found in consumer buying.

12. Risks: In addition, Moriarty (1983) stated that personal and organizational risks of a company decision generally are much greater than those faced by a typical consumer.

The significant differences between theses two types of markets has led many researchers to believe that industrial buyers' technical knowledge will moderate the price-perceived quality effect. However, very few have formally studied this situation. Substantial research on consumer behavior has tried to explain the final consumer's price-perceived quality effect. The price-perceived quality effect is the relationship that exists when price is positively correlated to perceived quality. The effects of extrinsic (price, brand name, store name) and intrinsic cues (part of the physical product) on the consumer's perception of product quality have divided the study of quality perception into two research streams. One research stream stresses the significance of extrinsic cues on price-perceived quality, and the second research stream focuses the significance of intrinsic cues on price-perceived quality. When considering the effect of extrinsic cues, it has been proven that the price-perceived quality effect is positively significant. However, when considering the effect of intrinsic cues, researchers have found that price-quality effect loses its significance, and that intrinsic cues have a larger impact on the perception of quality. 


\subsection{OBJECTIVE OF STUDY}

The objective of this study was to establish how technical knowledge moderates the price-perceived quality effect in an industrial setting. This study examined the relationship between an industrial buyers' relevant technical knowledge and the price-perceived quality effect. It was hypothesized that the price-perceived quality effect will lose its significance in an industrial setting as technical knowledge increases.

\subsection{SIGNIFICANCE OF STUDY}

According to Moriarty (1983), industrial marketers spend much of their time developing complex marketing strategies to improve their positions in the market. The ultimate targets of these strategies are individuals or groups of individuals in other organizations who will decide whether to buy marketer's products. Most of the marketers' energies go into manipulating various parts of the marketing mix, with very little time spent on understanding the behavior of the people who make the purchase decisions. Industrial-marketing strategies reflect an implicit understanding of organizational buying behavior, developed through experience, direct contact, and intuition. By contrast, the marketer of consumer goods typically devotes substantial resources to understanding what makes consumers buy. A clear understanding of consumer behavior has been very helpful to consumer marketers. It seems reasonable that a similar understanding of organizational buying behavior should also be equally helpful to industrial marketers. 
Moriarty (1983) also stated that one of the primary objectives of research in both consumer behavior and organizational buying behavior is to understand how buyers evaluate, select products, and form their quality impression. Research on consumer behavior has made great strides toward understanding how individuals evaluate product offerings and how to capture data on consumer preferences in market research. This understanding has been put to widespread use in consumer marketing (marketing strategies). However, any effort to apply consumer marketing approaches to analysis of industrial markets must confront substantial difference between the buying behavior of organizations and that of individuals.

Consequently, the concern of product quality has increasingly attained a more significant role in American corporations. In confronting the growing industrial buyers' demand for product quality, it is important to study industrial behavior in terms of how they view product quality (Scheuing, 1989). Industrial buyers are interested in quality as they are in the price of the product. Indeed, many industrial buyers are willing to pay more for an item that satisfies their requirements. In fact, Scheuing (1989) stated that a company with superior quality has a competitive edge over the market place.

In order to satisfy industrial buyers' expectations and be successful in the long run, the industrial marketer must first determine what those expectations are and define them as explicitly as possible (Scheuing, 1989). The higher the level of technical knowledge, the more precise the industrial buyer can be in specifying his/her needs and requirements to the industrial marketer. When the industrial marketer's identifies the industrial buyer's expectations, a close customer-supplier relationship will develop. Consequently, the industrial marketer enhances its 
position in the marketplace.

Since the identification of the industrial buyers' expectations is the task of the industrial marketer (Scheuing, 1989), the documentation of industrial buyer's expectations and requirements is referred to as a specification. The document clearly describes the customer requirements and defines in explicit detail the materials, the manufacturing operations, and the testing procedures to be utilized in measuring the fulfillment of these requirements. The completeness and accuracy of a specification and absolute adherence to each of the requirements it contains are keys to achieving product quality. Since purchasing has to communicate the desired quality level to suppliers, the firm's engineering department is responsible for the accuracy of the specification. Again, it is critical that the industrial buyer be knowledgeable about the product in order to provide accurate specifications. If the industrial buyer lacks technical knowledge about a given product, a poor purchase decision will be made which, in turn, may increase production costs or lower the quality of the end product. For example, in a carpet manufacturing process, if the industrial buyers do not provide the yarn suppliers with the exact descriptions of the yarn components needed for a particular carpet style, poor quality yarn will be bought. Consequently, hundreds of yarn ends that are fed into the tufting machines (sewing machines) will rupture causing the machines to breakdown; thus, causing delays in production. Furthermore, even if the yarn ends do not rupture, a defective second grade product will result. Delays in production and poor quality products will decrease the company's profitability. 
Since industrial marketers need to fully satisfy the requirements of the industrial buyer, the industrial marketers must study the industrial buying behavior and determine the factors that influence industrial buyers to form quality impressions. When industrial marketers identify the key factors that cause industrial buyers to form quality impressions, they can supply the industrial buyer with the relevant technical information to guide them in their purchase decisions. If industrial buyers are supplied with adequate technical information, they will be better apt to make superior quality decisions. However, this assumption only holds true if the industrial buyer possesses a high degree of technical knowledge about the product or product category. On the other hand, if an industrial buyer lacks technical knowledge about the product, no matter how much technical information is supplied to him/her, the industrial buyer will be unable to understand the technical information; consequently, the industrial buyer will make poor quality decisions. 


\section{CHAPTER 2: LITERATURE REVIEW}

Monroe and Krishnan (1985) state that perception is a process of organizing, interpreting, and deriving meaning from stimuli through the senses. In addition, sensation is a process of receiving these sense impressions; however, individual needs, memories, and experiences also influence perception. They also concluded that perceived product quality is the perceived ability of the product to provide satisfaction relative to the available alternatives.

Perception is an important determinant of buyer behavior; furthermore, in order to differentiate among products and to form impressions of product quality, consumers use cues such as product characteristics, store images, brand names, and prices. However, one must understand how consumers actually perceive these cues since cues that are not perceived cannot influence final consumers' buying behavior. Price is one cue that buyers use the most in making purchase decisions.

According to Monroe and Krishnan (1985), the key to understanding the effect of price on final consumers' decisions is that price may serve as a cue whereby the consumer can predict the quality of the product. Scitovsky (1945) introduced the concept of priceperceived quality relationship. He argued that judging quality by price merely implies a belief that price is determined by the competitive interplay of the forces of supply and demand. Following Scitovsky's rationale, several researchers have empirically tested the hypothesis that price is positively related to perceived quality. This relationship is called the price-perceived 
quality effect.

Several studies including those by Gardner (1970, 1971), Deering and Jacoby (1972), Raju (1977), Lambert (1970, 1972), Bettman (1973), Shapiro (1970), Jacoby, Olson, and Haddock (1971), Valenzie and Andrews (1971), Wheatley, Chiu, and Goldman (1981), McConnell (1968), Lauridsen (1973), among others, have relied on Leavitt's (1954) hypothesis that price is the only available differential information when consumers feel some conflict in making a choice; thus, they would sometimes select the higher-priced product.

Shapiro (1972) extended the theory to that of a perceived risk by suggesting that consumers perceive a product as a set of information cues. Each cue is evaluated as to whether it has a predictive value (how close the cue matches a desired product attribute) and a confidence value (the consumers' ability to evaluate the cue itself). Since price is considered to be a high confidence cue, it is normally used to attribute quality to the product.

Steenkamp (1990) states the need to consider how consumers form quality attribute beliefs in order to understand how consumers arrive at quality judgments. Therefore, it is imperative to distinguish between quality cues and quality attributes. Quality cues are informational stimuli that are related to the quality of the product. They can be ascertained by the consumer through the senses prior to consumption. On the other hand, quality attributes are the functional and "psycho" social benefits provided by the product. They represent what the product is perceived as doing for the consumer. Quality attributes are unobservable prior to consumption. In other words, quality cues are what the consumer observes about the product, whereas quality attributes are what the consumer wants of the product. 
According to Steenkamp (1990), the relationship between quality cues and quality attributes can be conceptualized as means-end chains. Quality cues are important only to the extent that they are perceived as meeting certain needs that are valued by the final consumer.

Quality cues can be classified as either intrinsic or extrinsic (Olson, 1972; Olson and Jacoby 1972). Intrinsic cues are part of the physical product and cannot be changed without also changing the product itself. For example, for detergents, color, suds, and smell are intrinsic cues. On the other hand, extrinsic cues are related to the product, but are not physically part of it (price, brand name, country of origin, and store name).

Several studies have manipulated intrinsic cues while testing for the price-perceivedquality relationship [Valenzie and Andrews (1971), Jacoby et al. (1971), Rao (1971), Valenzie and Eldridge (1973), Cimbalo and Webdale (1973), Szybillo and Jacoby (1974), Pincus and Waters (1975), Wheatley, et al. (1981)]. With one exception (Valenzie and Eldridge, 1973), all the studies found significant intrinsic cue effects. Four of the studies [Valenzie and Andrews (1971), Valenzie and Eldridge (1973), Cimbalo and Webdale (1973), Wheatley et al. (1981)] found price to have a significant effect on quality perception. Valenzie and Andrews (1971) and Jacoby et al. (1971) found interactions between price and product samples.

Olson (1972) hypothesized that for most products, intrinsic cues are more important in the quality perception process than extrinsic cues. This was again confirmed in a follow up study by Olson and Jacoby (1972). In addition, Olson states that intrinsic cues are likely to have a stronger impact on quality evaluation because they have a higher "predictive" value that is, consumers perceive or believe that this cue is strongly indicative of the product 
characteristic (e.g., quality) in question (Olson, 1977; Cox, 1962). His hypothesis has received considerable support for a variety of products: nylon hose (Szybillo and Jacoby, 1974), ballpoint pens (Pincus and Waters, 1975), carpet (Wheatley, et al., 1981), envelopes (Jon and Jolibert, 1983), and skirts (Davis, 1985).

Contrary from Olson's hypothesis that for most products intrinsic cues are more important in the quality perception process than extrinsic cues, other quality-perception studies have suggested that consumers' quality perceptions are strongly affected by extrinsic cues such as price, brand name, and retail store reputation [Wheatley and Chiu (1977), Jacoby et al. (1971), Andrews and Valenzie (1970, 1971), French, Williams, and Chance (1972), McConnel (1968), Stafford and Enis (1969), Valenzie and Andrews (1971)], and that intrinsic cues have a negligible effect on quality perceptions (Peterson, 1970).

In addition, Akshay R. Rao and Kent B. Monroe (1989) performed an analysis which suggests that, for consumer products, the relationship between price and perceived quality and between brand name and perceived quality are positively and statistically significant. However, the positive effect of store name on perceived quality is small and not significant.

Quality attributes are classified as either experience or credence attributes [Darby and Karni, (1973), Nelson, $(1970,1974)]$. Experience attributes can be verified on the basis of experience with the product. Some examples of experience attributes are the fuel consumption of a car, the beauty of a painting, and the cleaning power of a detergent (Steenkamp, 1990). Credence attributes cannot be ascertained even after a long period of time and/or by consulting an expert. Some examples of credence attributes are the durability of a car, harmfulness of 
cigarettes, and the financial security of investments (Steenkamp, 1990).

Olson (1973) argued that consumers use a variety of cues to infer product quality. For example, price, brand name, and store name (extrinsic cues) as well as nutritional content (intrinsic cue) would be used by consumers in their assessment of the quality of a breakfast cereal. Therefore, because several cues affect quality perceptions, the use of multiple independent variables in addition to price cue is necessary for valid empirical tests (Rao and Monroe, 1989). Single-cue price-quality studies have been considered somewhat artifactual. In the absence of any other information, subjects would naturally exhibit a positive price quality effect (Enis and Stafford, 1969). Therefore, Rao and Monroe (1989) infer that single-cue price-perceived quality studies should manifest larger effects than multicue studies.

Several studies have been concerned with consumer perception of price as an indicator of quality, and many of these studies have shown price to operate in this manner (Monroe, 1973). However, whether price is used as a quality signal, and the extent of this usage, appears to depend on the availability of other signals (Erickson and Johansson, 1985). For example, Szybillo and Jacoby (1974) showed that cue for physical differences and store image causes price to become an insignificant indicator of product quality. In addition, when information on quality-related attributes is readily available, one would accordingly expect price to lose its significance (Erickson and Johansson, 1985).

A major factor that may explain the differences in consumers' reliance on price for predicting quality is the variability in their perception of product quality (Etgar and Malhotra, 1981). As suggested by Olson and Jacoby (1972), the concept of product quality carries 
diverse connotations. Quality cues differ in terms of the information content they carry (Etgar and Malhotra, 1981). Consequently, their predictive values (Cox 1962; Olson and Jacoby 1972) are the degree which the consumer believes and perceives that a cue is indicative of a given notion of product quality. Consumers interested in different aspects of product quality can, therefore, be expected to search for, and utilize, different quality cues; in addition, reliance on price as a predictive cue can be expected to vary among consumers

In summary, several studies have tried to clarify the final consumer's perception of product quality. Two main research streams have evolved. The first research stream has evolved from considering the effect of extrinsic cues (price, brand name, store name, etc.) on the consumer perception of product quality. It has been proven that the price-quality effect is positively significant. The second research stream has evolved from considering the effect of intrinsic cues (part of the physical product) and determining that intrinsic cues have a greater impact on perceived product quality; therefore, price loses its significance in the priceperceived quality effect. Both research streams have failed to address the effect of other factors (prior knowledge, involvement, level of education, etc.) while studying the priceperceived quality effect. Prior knowledge about the product is an important factor in the consumer's ability to process information (Celsi and Olson, 1988). A person with more prior knowledge tends to have richer and interrelated schemata of product-related cognitions and enables processing of (new) quality related information at a deeper, more abstract, and more elaborate levels (Marks and Olson, 1981). Since almost no study has investigated the association between knowledge when studying the price-perceived quality effect, this study 
examined the relationship between technical knowledge and the price-perceived quality effect in an industrial setting. 


\section{CHAPTER 3: RESEARCH METHODOLOGY}

This chapter presents the methodology of the study by outlining the study population, the measuring instrument, data collection procedures, and analytical techniques used to test the research hypotheses.

\subsection{STUDY POPULATION}

The goal of this study was to investigate the relationship between technical knowledge and price-perceived quality in an industrial setting. Since more than half of the nations industrial buyers are concentrated in seven states: New York, California, Pennsylvania, Illinois, Ohio, New Jersey, and Michigan (Kotler, 1988), one difficulty found in the course of this study was the enactment of an industrial setting in the City of Miami. Thus, a model to emulate an industrial setting was devised using engineering students and professors. Engineering students and professors were chosen because engineers usually participate in making buying decisions in industry. They help define specifications and also provide information for evaluating product alternatives.

Judgment sampling was used in selecting the most appropriate configuration of the sample. Judgment sampling is the procedure in which the researcher focuses on a subset of the population to form his/her sample instead of focusing on the entire population (random sampling) (Parasuraman, 1986). A sample of this population was presented with the need to 
purchase a computer system for a hypothetical organization. The sample consisted of 153 students and professors at Florida International University. Since it was hypothesized that as technical knowledge increases price will lose its significance as a quality indicator, it was crucial to survey technically oriented subjects who would have the same characteristics as an industrial buyer. In addition, it was important to survey a diversity of engineering classes from different fields of study. Some fields of study are more technically inclined than others. On the other hand, random sampling would have been ineffective because the final sample might have included non-technically oriented subjects; therefore, the sample would have not been representative of the industrial buyer population (influencers).

\subsection{MEASUREMENT INSTRUMENT AND PROCEDURES}

A two tier questionnaire was used to gather information. The first tier determined the level of technical knowledge of the respondent (industrial buyer). A questionnaire of 17 multiple choice and 12 true and false questions about computer terms was developed. These terms were taken from several dictionaries of computer terminology including those by Downing and Covington (1992) and Freedman (1991). Appendix A gives the questionnaire used.

The second tier evaluated the presence of technical attributes in relation to priceperceived quality effect in an industrial setting. Appendix B gives the questionnaire used. In the second tier, the subjects were presented with the following problem: 
"Company XYZ is interested in creating multimedia courseware. This courseware will be used for the company's training program. In order to develop this courseware, the company needs new equipment."

In addition, each subject was given the following general need description:

"A computer system capable of importing video and audio from a VCR to a hard drive and providing full editing of the video and audio then exporting it back to VCR format. Multimedia software available on compact disks has been already been purchased for this application."

Knowing all this information, the subjects were told that they were to purchase the best quality computer that met the needs of the company. They were asked to examine the four computer models given in Table 3-1: 
Table 3-1 Computer Model Descriptions

\begin{tabular}{|c|c|c|c|}
\hline MODEL A & MODEL B & MODEL C & MODEL D \\
\hline 486 DX2-66, MULTIMEDIA & INTEL 66MHz 80486DX2 & INTEL 486 DX2/66 MHZ & 433/L /486 / $33 \mathrm{MHZ}$ \\
\hline $8 \mathrm{MB}$ & $8 \mathrm{MB}$ & $8 \mathrm{MB}$ & $4 \mathrm{MB}$ \\
\hline $426 \mathrm{MB}$ & $340 \mathrm{MB}$ & $340 \mathrm{MB}$ & $210 \mathrm{MB}$ \\
\hline $\begin{array}{l}\text { 5.25" EPSON FLOPPY, } \\
\text { 1.44MB 3.5" }\end{array}$ & 1.2MB 5.25" & 1.44MB 3.5" & $1.44 \mathrm{MB} 3.5^{\prime \prime}$ \\
\hline 15" COLOR MONITOR & $\begin{array}{l}\text { 14" SVGA COLOR } \\
\text { MONITOR }\end{array}$ & 14" COLOR MONITOR & $\begin{array}{l}\text { ULTRASCAN 14ES } \\
\text { COLOR MONITOR }\end{array}$ \\
\hline $1024 \times 768$ & $800 \times 600$ & $1024 \times 768$ & $1024 \times 768$ \\
\hline Dot Pitch $=.28$ & Dot Pitch $=.39$ & Dot Pitch $=.28$ & Dot Pitch $=.39$ \\
\hline $2 \times \mathrm{CD}-\mathrm{ROM}(350 \mathrm{KPS})$ & $\begin{array}{l}\text { DOUBLE SPEED } \\
\text { CD-ROM ( } 300 \mathrm{KPS})\end{array}$ & SONY CDU 33A (300KPS) & $\begin{array}{l}\text { DOUBLE SPEED CD-ROM } \\
(300 \mathrm{KPS})\end{array}$ \\
\hline $\begin{array}{l}1 \text { MB DIAMOND } \\
\text { SPEEDSTAR PRO VLB }\end{array}$ & INCLUDED & MEDIAVISION PRO 16 & PROMOVIE STUDIO II \\
\hline $\begin{array}{l}\text { DIAMOND SONIC LX } \\
\text { DIGITAL STEREO }\end{array}$ & $\begin{array}{l}\text { 16-BIT(SOUNDBLASTER } \\
\text { COMPATIBLE) }\end{array}$ & INCLUDED & $\begin{array}{l}\text { SOUNDBLASTER } 16, \\
\text { PANASONIC }\end{array}$ \\
\hline RS $101 \mathrm{KEY}$ & $\begin{array}{l}\text { 124-KEY ANYKEY } \\
\text { PROGRAMMABLE }\end{array}$ & 101 KEY WORKSTATION & $\begin{array}{l}101 \text { KEYBOARD, 6-PIN, } \\
\text { QUIET KEY }\end{array}$ \\
\hline KOSS 8-WATT & $\begin{array}{l}\text { SOUNBLASTER } \\
\text { COMPATIBLE }\end{array}$ & LABTEC & $\begin{array}{l}\text { PEAVEY MEDIAVOICE } \\
200 \text { AMPS SPEAKERS }\end{array}$ \\
\hline MICROSOFT 2.0 & MICROSOFT & INCLUDED & INCLUDED \\
\hline $\begin{array}{l}\text { MS-DOS } 6.2 \& \\
\text { WINDOWS FOR } \\
\text { WORKGROUPS } 3.11\end{array}$ & $\begin{array}{l}\text { DOS } 6.2 \text { \& MICROSOFT } \\
\text { WINDOWS FOR } \\
\text { WORKGROUPS } 3.11 \\
\text { MS MULTIMEDIA } \\
\text { WORKS ON CD }\end{array}$ & $\begin{array}{l}\text { MULTIMEDIA } \\
\text { ENCYCLOPEDIA } \\
\text { DOS 6.0, WINDOWS } 3.1\end{array}$ & DOS 6.21, WINDOWS 3.1 \\
\hline$\$ 2,500.00$ & $\$ 2,400.00$ & $\$ 2,800.00$ & $\$ 2,600.00$ \\
\hline
\end{tabular}


The subjects were then asked to rank the importance of 10 attributes in making the final decision. The attributes are Processing Speed, RAM Size, Hard Drive Size, Floppy Drive Size, Monitor Size, Monitor Resolution, CD-ROM Speed, Price, Video Card, and Hardware Compatibility. These attributes were chosen because computer vendors provide information on these attributes in marketing their products.

An individual's overall attitude toward an object (computer model) is determined by his/her attitude towards each attribute. The importance of the attribute is frequently referred to as attribute salience. In order to measure the attitude toward each computer model, a semantic differential scale was devised. The semantic differential scale consists of a series of items to be rated by the subjects. The three basic features of the semantic-differential scale are (Parasuraman, 1986):

- A series of bipolar adjectival words or phrases that pertain to the attitude object. They were identified as High/Low Processing Speed, Small/Large RAM Size, Large/Small Hard Drive Size, Single/Multiple Disk Drive Assortment, Large/Small Computer Monitor, Low/High Resolution, High/Low CD-ROM Speed, and Low/High Prices.

- Each pair of opposite adjectives was separated by a seven-category scale, with numerical labels.

- Some of the favorable descriptors were placed on the right-hand side, while others were reversed, (favorable descriptors appearing on the left hand side), to make the scale a balanced one. This reduces the chances of "acquiescence" bias that can occur if the statements are in the same direction. Studies have shown that respondents, especially 
those with low levels of education, have a tendency to agree with whatever side is presented by one-sided questions.

The respondents were asked to check one of the seven categories that best describes their views about each computer model along the continuum implied by the bipolar adjectives. Once the responses were obtained on all items, an overall attitude score for each respondent was computed. A more common application of the semantic scale, however, is to develop a pictorial profile (see Figure 4-4) of the attitude object(s) based on the mean ratings on the individual items.

\subsection{ANALYTICAL TECHNIQUES}

Correlation and regression techniques are statistical tools that are particularly useful in quantifying relationships between a single dependent variable and one or more independent variables. Because of their flexibility and ease of use, correlation and regression methods are relevant to a wide range of marketing research problems. Microsoft Excel's statistical package was used to perform the statistical analysis.

Since consumer's behavior on price-perceived quality effect is linear, a simple linear regression model was developed to observe the relationship between price and quality in an industrial setting. We expected the relationship between price and perceived quality to lose its direct linear effect in an industrial setting. Hypotheses on the regression coefficient were established to test if there was no direct relationship between price and perceived quality. The null hypothesis $\left(\mathrm{H}_{0}: \beta_{1} \geq .25\right)$ states that there is a direct relationship between price and quality, 
whereas the alternative hypothesis $\left(\mathrm{H}_{1}: \beta_{1}<.25\right)$ states that there is no direct relationship between price and quality. $\beta<.25$ is chosen because at this level the relationship between the independent variable (price) and the dependent (perceived quality) lost its strong correlation and was found to be moderately weak.

A $95 \%$ certainty was chosen; thus, the significance level $(\alpha)$ is .05 , or $5 \%$. The significance level is the probability of concluding that there is no linear relationship when in fact there is one. Usually researchers chose a certainty of $95 \%$ or $99 \%$. In this specific experiment, $90 \%, 95 \%$, and $99 \%$ levels of certainty generated the same conclusions.

The critical region, or rejection region, consists of a set of values that constitute sufficient evidence for the researcher to be $95 \%$ sure that $\mathrm{H}_{1}$ is true. For this regression problem, the Student's $t$-distribution was utilized to obtain the value of $t_{\mathrm{v}, \alpha}$ critical. We define $t_{\mathrm{v}, \alpha}$ to be the value of $t$ with $\mathrm{v}$ degrees of freedom and $\alpha$ significance level. The degrees of freedom is equal to $\mathrm{n}-(\mathrm{k}+1)$, where $\mathrm{k}$ is the number of variables in the regression analysis and $\mathrm{n}$ is the number of data points. Therefore, $t{ }_{104,05}=1.6645$. The value of test statistic was determined as follows (Mendenhall and Sincitt, 1992):

$$
t_{(\text {observed })}=\frac{\text { sample slope coefficient }(\mathrm{b})-\text { hypothesized value of } \beta}{\text { standard error of the slope }}
$$

A comparison of test statistic to the critical region was performed in order to reject $\mathrm{H}_{0}$ if $t_{\text {(observed) }}<-t_{104,05}$.

In addition, $\mathrm{R}^{2}$ is computed as the coefficient of determination to find the proportion of the sum of squares of deviations that could be attributed to the independent variables, e.g. 
quality can be fully derived from price. If $\mathrm{R}^{2}$ is 1 , there is a perfect correlation between the $\mathrm{x}$ and $y$ variables. At the other extreme, if the coefficient of determination is 0 , the regression equation is not helpful in predicting a $y$-value. The closer $R^{2}$ is to 1 , the stronger the relationship between the two variables $\left[\mathrm{R}^{2}=\mathrm{SS}_{(\text {regression) }} / \mathrm{SS}_{(\text {total) })}\right]$

In addition, a multiple linear regression model was devised to study the relationship between the subject's technical knowledge and price-perceived quality. Hypothesis tests of significance of the regression model were done to test if a relationship existed between technical knowledge and price-perceived quality effect. Before testing each independent variable separately, we tested the significance of the regression. This test would indicate if any of the independent variables is significantly different from zero. Since we found that one of the independent variables was significant, then we turned to the question of which one. If the test of significance would have not detected any significant independent variables, however, then further testing would have been unnecessary. The null and alternative hypotheses were as follows:

$$
\begin{aligned}
& \mathrm{H}_{0}: \beta_{1}=0 \\
& \mathrm{H}_{1}: \beta_{1} \neq 0
\end{aligned}
$$

The null hypothesis states that there is no direct relationship between technical knowledge and price-perceived quality, and we hope this is a false statement. The alternative hypothesis is a statement of the experimental hypotheses, or what we expect to be true. Again, in the multiple regression, we used the significance level of $(\alpha) .05$, or $5 \%$. 
For this regression problem, the $F$-distribution was utilized to obtain the critical value of $F_{\mathrm{vl}, \mathrm{v} 2, \alpha}$ (value of $F$ with vland v2 degrees of freedom at an $\alpha$ significance level.) The value of test statistic is as follows:

$$
F_{(\text {observed })}=\frac{M S_{(\text {regression })}}{M S_{(\text {residual })}}
$$

The comparison of test statistic to the critical region is: reject $\mathrm{H}_{0}$ if $F_{\text {(observed) }}>F_{2,103,05}$. Since $F_{\text {(observed) }}$ was greater than $F_{2,103,05}$, we rejected $\mathrm{H}_{0}$. Therefore, we were $95 \%$ sure that at least one of the variables is significant. Now, we proceeded to test the significance of each variable. But the coefficient of determination, $\mathrm{R}^{2}$, was first calculated in order to decide if technical knowledge and price-perceived quality were correlated. Since $R^{2}$ is found to be highly uncorrelated, then the $t$-test is used to test the hypothesis on the regression coefficients (price and technical scores independently). The following null and alternative hypotheses were use to test both the price and technical knowledge coefficients.

$$
\begin{aligned}
& H_{0}: \beta_{1} \geq 25 \text { (Direct relationship) } \\
& H_{1}: \beta_{1}<.25 \text { (No linear relationship) }
\end{aligned}
$$

The comparison of test statistic to the critical region is: reject $\mathrm{H}_{0}$ if $t_{\text {(observed) }}<-t_{\text {(critical). }}$ Once it was determined that a positive linear relationship did not exist between price and quality or between technical knowledge and price-perceived quality effect, a graphical assessment of the data determined the behavior of price-perceived quality in an industrial setting as technical knowledge increases 
The Semantic Scale statistical techniques were used to depict the most salient attributes that the subjects used in helping them determine their attitude toward each model and finally making the best purchase decision. Once the salient attributes were found, the Pearson product moment coefficient of correlation ( $r$ ) was used to measure the association between quality and price, quality and processing speed, quality and RAM size, quality and Hard Drive size, and Quality and CD-ROM speed. The correlation coefficient provides a quantitative measure of the strength of the linear relationship among $x$ and $y$ in the sample. The correlation coefficient $r$ is dimensionless, $R=\sqrt{S S_{\text {(regression) }} / S S_{(\text {total })}}$. The value of $\mathrm{r}$ is always between -1 and +1 . The closer $r$ is to 1 or -1 , the stronger the linear relationship between $y$ and $x$. Positive values of $r$ would imply that $\mathrm{y}$ increases as $\mathrm{x}$ increases; whereas negative values of $\mathrm{r}$ would imply that $\mathrm{y}$ decreases as $\mathrm{x}$ increases. Unlike $\mathrm{R}^{2}$, the correlation coefficient of $\mathrm{r}$ indicates the direction of the relationship between variables.

The following chapter presents the research findings. These findings evaluated the relationship between technical knowledge and price-perceived quality effect in an industrial setting. Regression and the other statistical models discussed in this chapter were used for this assessment. 


\section{CHAPTER 4: RESEARCH FINDINGS}

This chapter presents the analyses and findings of the investigation. First, background information of the subjects is described, followed by the descriptive statistics of the technical scores. Then, attribute analysis identifies the most important of the technical attributes that guide the industrial buyer in their purchase decisions, followed by the Semantic Differential Scale Analysis which determined the industrial buyers' overall opinion of the computer models. Results from the regression models and graphical assessment of technical knowledge are discussed.

\subsection{BACKGROUND INFORMATION OF RESPONDENTS}

The background data is summarized in Tables $4-1$ to $4-4$. The majority $(70.6 \%)$ of the subjects were male. In terms of the level of education, $3.3 \%$ of the study population had a Doctor of Philosophy degree, $9.8 \%$ of the participants were working towards their master's degree, and $76.4 \%$ were working on their baccalaureate degree. $34 \%$ of the subjects were pursuing their degrees in Electrical Engineering, 28.1\%. in Industrial Engineering, 13.7\% in Mechanical Engineering, 7.8\% in Civil Engineering, and 4.6\% in Computer Engineering.

$33.3 \%$ of the questionnaires were administered in Electrical Engineering classes, $33.4 \%$ in Industrial Engineering classes, and $29.4 \%$ were in Mechanical Engineering classes.

In this study, we surveyed respondent's from a diversity of engineering fields. Due to 
the nature of the engineering fields, Industrial Engineers, Mechanical Engineers, and Electrical Engineers are suspected to be more involved in an industrial purchase than any other type of engineers. In this sample, the highest percentage of respondents surveyed were encountered in the Electrical, Industrial, and Mechanical Engineering fields with $34 \%, 28.1 \%$, and $13.7 \%$ respectively. Therefore, we can say that the sample taken is sufficiently representative of industrial buyers.

$52.9 \%$ of the subjects have been involved in the purchase of a computer system for personal use. Only $15.7 \%$ of the subjects have been involved in the purchase of computers for business use. .

Table 4-1 Level of Education

\begin{tabular}{lcr}
\hline Professor & 5 & $3.3 \%$ \\
Graduate & 15 & $9.8 \%$ \\
\hline Undergraduate & & \\
1st year & 6 & $3.9 \%$ \\
2nd year & 8 & $5.2 \%$ \\
3rd year & 38 & $24.8 \%$ \\
4th year & 63 & $41.2 \%$ \\
Other & 2 & $1.3 \%$ \\
No Answer & 16 & $10.5 \%$ \\
\hline TOTAL & 153 & $100.0 \%$ \\
\hline
\end{tabular}

Table 4-2 Field of Study

\begin{tabular}{lcr}
\hline Mechanical Engineering & 21 & $13.7 \%$ \\
Industrial Engineering & 43 & $28.1 \%$ \\
Civil Engineering & 12 & $7.8 \%$ \\
Electrical Engineering & 52 & $34.0 \%$ \\
Computer Engineering & 7 & $4.6 \%$ \\
Other & 1 & $.7 \%$ \\
Not Specified & 17 & $11.1 \%$ \\
\hline TOTAL & 153 & $100.0 \%$ \\
\hline
\end{tabular}


Table 4-3 Gender

\begin{tabular}{lcr}
\hline Males & 108 & $70.6 \%$ \\
Females & 24 & $15.7 \%$ \\
No Answer & 21 & $13.7 \%$ \\
\hline TOTAL & 153 & $100.0 \%$ \\
\hline
\end{tabular}

Table 4-4 Engineering Classes Surveyed

\begin{tabular}{lcr}
\hline Engineering Economy & 11 & $7.2 \%$ \\
Computer Design & 33 & $21.6 \%$ \\
Integrated Circuits & 18 & $11.7 \%$ \\
Industrial Financial Decisions & 22 & $14.4 \%$ \\
Manufacturing Automation & 1 & $0.7 \%$ \\
Quality Control & 17 & $11.1 \%$ \\
Dynamics & 30 & $19.6 \%$ \\
Thermodynamics & 15 & $9.8 \%$ \\
Faculty & 2 & $1.3 \%$ \\
Unknown & 4 & $2.6 \%$ \\
\hline TOTAL & 153 & $100.0 \%$ \\
\hline
\end{tabular}

\subsection{TIER 1: TECHNICAL SCORES}

In order to study the relationship between technical knowledge and price-perceived quality, the technical scores were tabulated for every subject. Not all technical scores $(n=153)$ were used in the analysis because some respondents did not complete the entire survey. Consequently, an analysis between each respondent's technical score and quality perception was not performed. The results indicated that the average of the technical scores was 68.51 with a standard deviation of 15.32 . The score that occurred with the greatest frequency was 68.97 with a minimum score of 24.14 and a maximum score of 100 . The lower quartile, $\mathrm{Q}_{\mathrm{L}}$, of the scores was 58.62 , i.e. twenty-five percent of the students scored less than 58.62. The 
midquartile (or median) was 68.97 , i.e. fifty percent of the students scored less than 68.97.

The upper quartile, $\mathrm{Q}_{\mathrm{U}}$ was 79.31 , i.e. seventy-five percent of the students scored less than

79.31. We are $95 \%$ confident that the true mean score will be between (65.59 to 71.43 ).

Our sample of 106 scores has an approximate mound-shape with a relative frequency distribution that has a mean $\mathrm{y}=68.51$ and standard deviation $\mathrm{s}=15.32$ (See Figure 4-1).

Figure 4-1 Relative Frequency Histogram for $n=106$ Scores

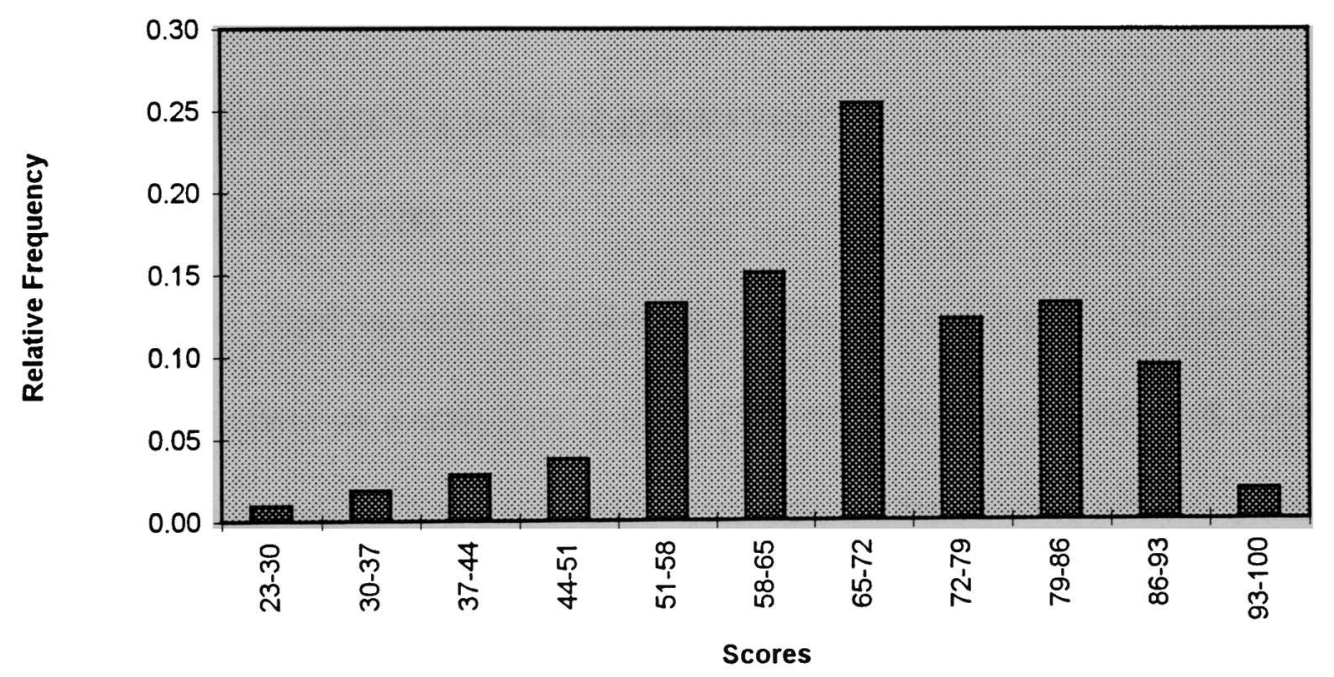

Figure 4-1 shows that this shape presents the properties of the Normal Distribution. Our data set follows very closely the following properties which include the rules listed below (Mendenhall and Sincich, 1988). Sixty-six percent of our data set lies within 1 standard deviation of their mean, $96.2 \%$ lies within 2 standard deviations of their mean, and $100 \%$ lies within 3 standard deviations of their mean. Therefore, we can say that the technical scores of 
the sample population are representative of the industrial buying population.

1. Approximately $68 \%$ of the measurements will lie within 1 standard deviation of their mean (i.e. within the interval $\mathrm{y} \pm \mathrm{s}$ for samples and $\mu \pm \sigma$ for populations).

2. Approximately $95 \%$ of the measurements will lie within 2 standard deviations of their mean (i.e. within the interval $y \pm 2 s$ for samples and $\mu \pm 2 \sigma$ for populations).

3. Almost all the measurements will lie within 3 standard deviations of their mean (i.e. within the interval $y \pm 3$ s for samples and $\mu \pm 3 \sigma$ for populations).

\subsection{TIER 2: PRICE-PERCEIVED QUALITY EFFECT}

\subsubsection{ATTRIBUTE RANKING}

Subjects were asked to rank the following attributes according to the importance in making the final purchase on a scale from 1 to 10 (1-most important, $2=2$ nd most important, and so on) :processing speed, RAM size, hard drive size, hardware compatibility, price, CDROM speed, monitor resolution, video card, monitor size, and floppy drive size. Table 4-5 describes the descriptive statistics for each of the 10 attributes. 
Table 4-5 Attribute Ranking Frequency and Statistics

\begin{tabular}{|c|c|c|c|c|c|c|c|c|c|c|c|c|}
\hline \multicolumn{11}{|l|}{ SAMPLE $(\mathrm{N}=131)$} & \multicolumn{2}{|c|}{ AVERAGE STD. DEV. } \\
\hline Rank $==>$ & 1 & 2 & 3 & 4 & 5 & 6 & 7 & 8 & 9 & 10 & & \\
\hline Processing Speed & 46 & 29 & 21 & 22 & 4 & 2 & 3 & 1 & 2 & 1 & 2.63 & 1.85 \\
\hline RAM Size & 16 & 44 & 27 & 18 & 13 & 10 & 2 & 0 & 1 & 0 & 3.09 & 1.61 \\
\hline Hard Drive Size & 7 & 17 & 24 & 19 & 19 & 12 & 14 & 9 & 6 & 4 & 4.73 & 2.35 \\
\hline Hardware Compatibility & 22 & 7 & 7 & 18 & 16 & 17 & 15 & 16 & 6 & 7 & 5.10 & 2.71 \\
\hline Price & 25 & 7 & 11 & 10 & 16 & 10 & 9 & 9 & 10 & 24 & 5.47 & 3.25 \\
\hline CD-ROM Speed & 4 & 12 & 15 & 9 & 18 & 26 & 12 & 13 & 14 & 8 & 5.72 & 2.46 \\
\hline Monitor Resolution & 3 & 2 & 14 & 13 & 19 & 16 & 22 & 20 & 16 & 6 & 6.18 & 2.22 \\
\hline Video Card & 8 & 10 & 8 & 12 & 9 & 16 & 21 & 11 & 19 & 17 & 6.24 & 2.76 \\
\hline Monitor Size & 1 & 3 & 2 & 4 & 7 & 10 & 19 & 38 & 27 & 20 & 7.66 & 1.93 \\
\hline Floppy Drive Size & 0 & 0 & 2 & 6 & 8 & 12 & 16 & 14 & 31 & 42 & 8.13 & 1.92 \\
\hline
\end{tabular}

After analyzing Table 4-5, Processing Speed received an average rank of 2.63 . Therefore, Processing Speed was considered the most important attribute in making the purchase decision. RAM Size, Hard Drive Size, Hardware Compatibility, and CD-ROM were also among the technical attributes that the subjects considered highly in making the purchase decision. On the other hand, price received an average ranking of 5.47. Price, in relation to previously mentioned attributes, lost its significance as a key determinant in making the purchase decision because other attributes became key quality indicators. It was surprising to find that the videocard card did not play an important role in the purchase of a multimedia system. This might have been caused by the lack of detailed information for this computer component. Monitor Resolution, Monitor Size, and Floppy Drive Size were among the least important attributes. These computer components were not the crucial components in meeting the requirements for the company. 
Figure 4-2 illustrates the number of respondents that fall in each one of the first five categories, whereas Figure 4-3 illustrates the other five categories. Processing Speed, RAM Size, Hard Drive Size, and Hardware Compatibility are among the most important attributes in making a purchase decision. Forty-six respondents categorized processing speed as rank number 1. As one can see, processing speed and RAM size have a high frequency of respondents categorizing rank 1 through rank 3, and the frequency continuously decreases from rank 4 through rank 10. Hard Drive size and Hardware Compatibility have more of a steady frequency from rank 1 through rank 7 , but begins to decline from rank $8-10$. On the other hand, price had relatively high frequencies at both extremes with moderately low frequencies from rank 2 through rank 9.

Figure 4-2 Technical Attribute Ranking Frequency (Part 1)

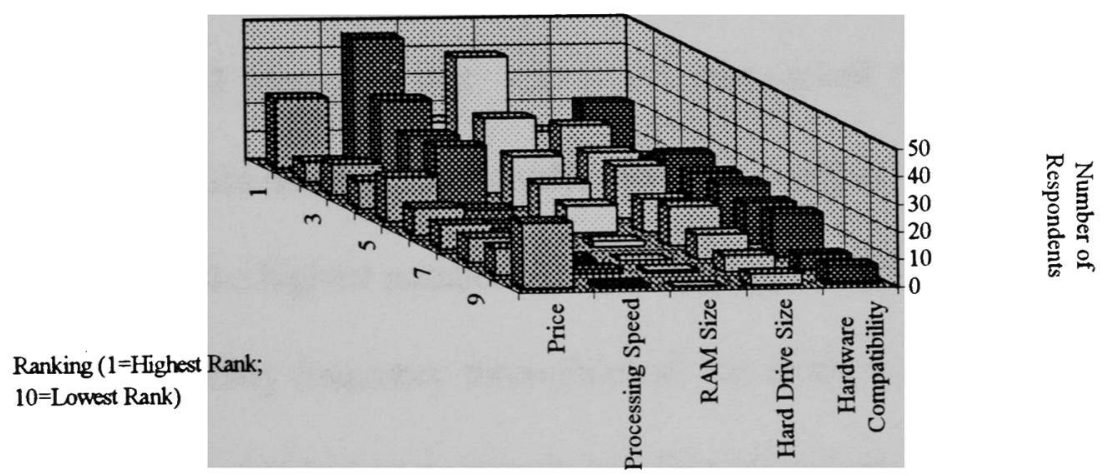


Figure 4-3 Technical Attribute Ranking Frequency (Part 2)

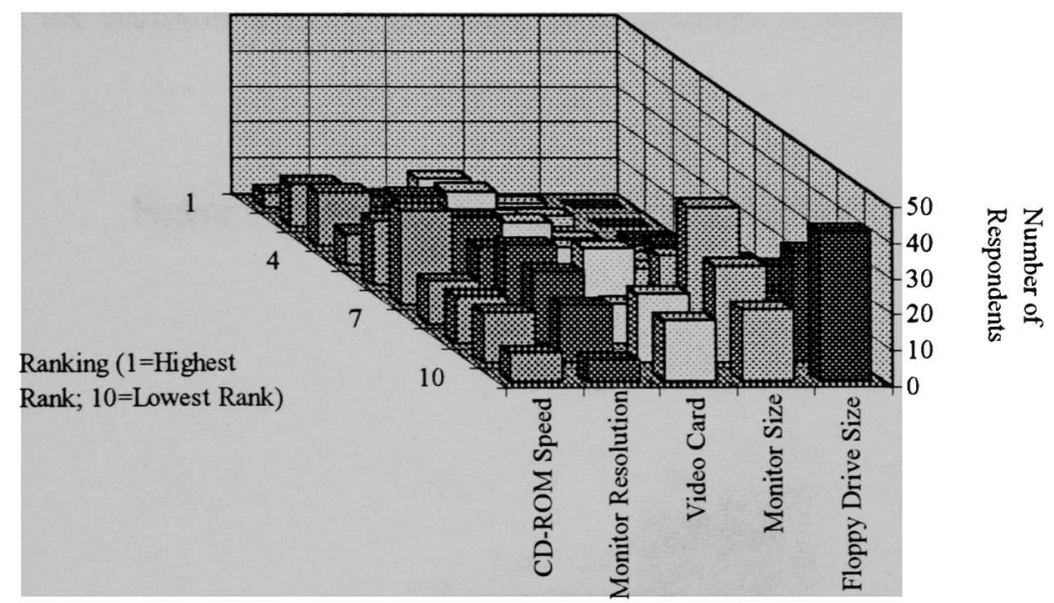

Figure 4-3 illustrates that CD-ROM was ranked one of the important attributes in making a purchase decision. Relatively, there is a steady increase from rank 1 through rank 6 . Rank 6 having the highest number of respondents (26). Monitor resolution and the videocard had mainly a steady frequency throughout all the category rankings. However, monitor size and floppy drive size had an extremely low frequency from category 1 through 7 with a sharp increase in frequency from category 8 through 10. 
The overall average quality ranking can be visualized in Figure 4-4. The respondents ranked the importance of the ten attributes in making a final decision. As the average quality ranking increases, the attribute becomes less importance attribute in the final purchase.

Figure 4-4 Average Quality Attribute Ranking

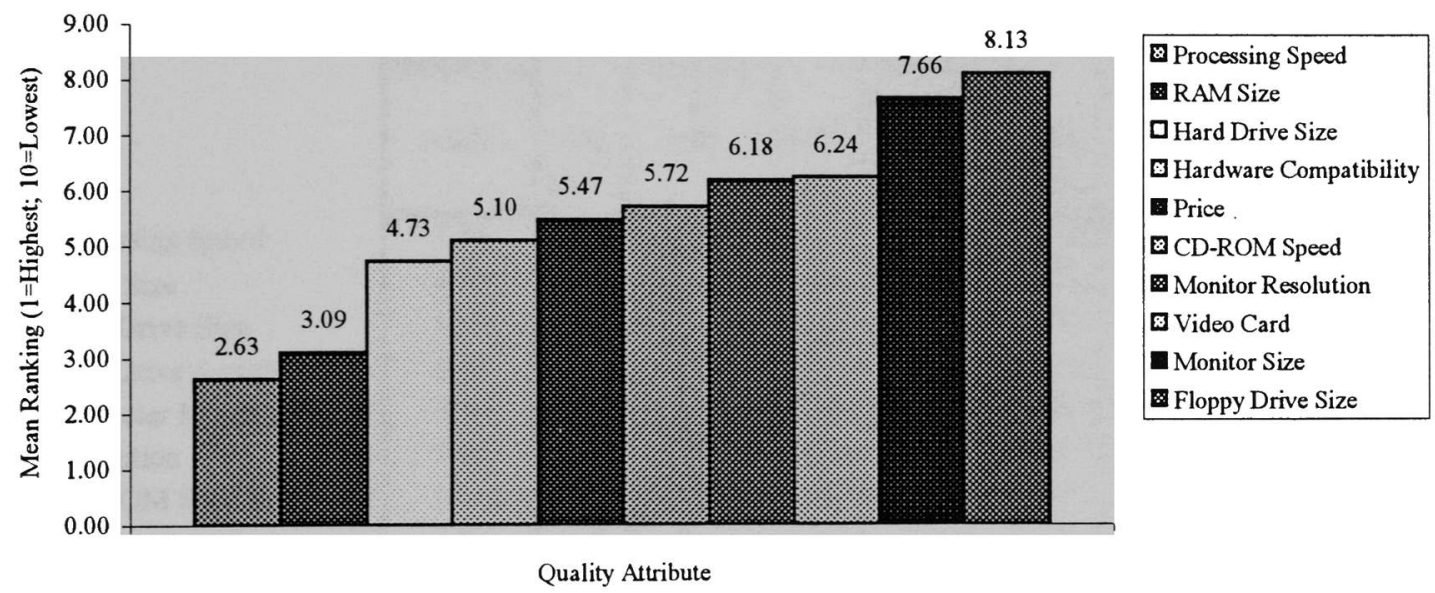

We have concluded from Figures 4-2 through 4-4, that price lost its significance as a quality indicator as other technical attributes gained more importance. These attributes include processing speed, RAM size, Hard Drive size, and Hardware compatibility. Now that technical attributes have been identified, the Semantic Differential Scale has determined the respondent's overall opinion of each model and has detected the most salient attributes which helped the respondents in forming their overall perception of each model. 


\subsubsection{SEMANTIC DIFFERENTIAL SCALE}

Based on the computer descriptions, each respondent provided their opinion of each model by using a scale from 1 to 7 . The higher the rank, the more favorable the opinion of each model.

Table 4-6 Semantic Differential Scale Statistics SAMPLE $(\mathrm{N}=93)$

Attributes

(1) Processing Speed

(2) RAM Size

(3) Hard Drive Size

(4) Disk Drive Assortment

\begin{tabular}{|c|c|c|c|c|c|c|c|}
\hline MODEL A & & $\begin{array}{c}\text { MODEL } \\
\text { B } \\
\text { AVG. }\end{array}$ & $\begin{array}{c}\text { STD. } \\
\text { AVG. }\end{array}$ & $\begin{array}{c}\text { MODEL } \\
\text { STD. } \\
\text { DEV. }\end{array}$ & $\begin{array}{c}\text { AVG. } \\
\text { STD. }\end{array}$ & $\begin{array}{c}\text { MODEL } \\
\text { DVG. }\end{array}$ & $\begin{array}{c}\text { STD. } \\
\text { DEV. }\end{array}$ \\
\hline \hline 5.98 & 1.46 & 5.60 & 1.74 & 5.72 & 1.62 & 3.73 & 1.88 \\
4.90 & 1.96 & 4.91 & 1.86 & 5.02 & 1.78 & 2.70 & 1.90 \\
5.52 & 1.90 & 4.58 & 1.39 & 4.53 & 1.37 & 3.48 & 1.98 \\
5.42 & 1.86 & 2.76 & 2.00 & 2.99 & 1.91 & 2.72 & 1.87 \\
5.16 & 1.70 & 3.96 & 1.79 & 4.06 & 1.76 & 3.69 & 1.78 \\
5.69 & 1.50 & 3.45 & 1.83 & 4.87 & 1.87 & 4.53 & 1.98 \\
5.16 & 1.94 & 4.59 & 1.56 & 4.30 & 1.60 & 4.33 & 1.60 \\
4.39 & 1.65 & 4.61 & 1.68 & 2.99 & 1.83 & 3.51 & 1.79 \\
\hline
\end{tabular}

(5) Computer Monitor Size

(6) Resolution

(7) CD-ROM Speed

(8) Price

4.39

1.65

4.59

These semantic differential scale statistics were used in developing the pictorial profile in

Figure 4-5. 
Figure 4-5 Semantic Differential Scale

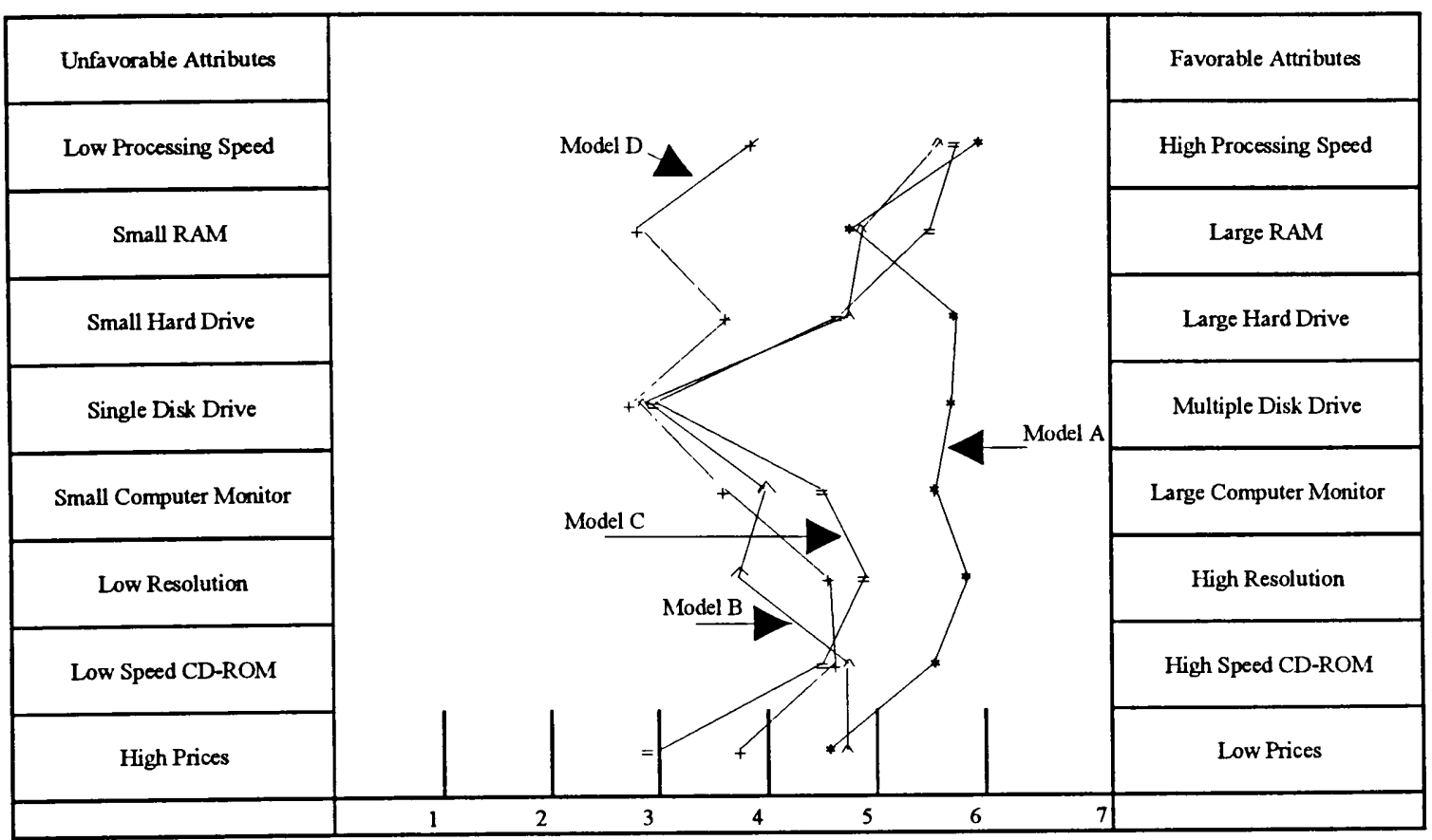

It can be noted that Processing Speed, RAM Size, Hard Drive Size, CD-ROM speed were salient attributes that helped the respondents in forming their perceptions about each of the computer models. Again, price was not one of the most salient attributes in forming each respondents' perceptions about each of the models. The previously mentioned salient attributes were more important quality attributes which caused price to lose its significance as a quality indicator. This results has confirmed the findings of the attribute ranking analysis.

The overall perception of each model is on a scale from 1-56. The higher the number, the more favorable the attitude. Respondents perceived Model A as the one with the best quality with an average overall perception of 42.22 . In addition, Model D was perceived to have the worst quality level with an average overall perception of 28.69. The overall 
perception of Model B (perception level $=34.47)$ and Model C (perception level $=34.48)$ was about the same because monitor resolution was the main difference between the models. Monitor resolution was one of the technical attributes which respondents felt least important when considering to make an industrial purchase.

\subsubsection{PERCEIVED QUALITY}

The subjects were asked to rank the four models on a scale from 1 to 4 . Number 1 being the first choice, number 2 the second choice and so on.

TABLE 4-7 Computer Models: Rankings

\begin{tabular}{|c|c|c|c|c|c|c|c|}
\hline \multicolumn{3}{|c|}{ RANKING FREQUENCY } & \multicolumn{2}{|c|}{ SAMPLE $(\mathrm{N}=96)$} & AVERAGE & REVERSED & STD.DEV \\
\hline & 1 & 2 & 3 & 4 & & & \\
\hline Model A & 68 & 12 & 12 & 4 & 1.4845 & 3.5155 & 0.88 \\
\hline Model B & 14 & 29 & 43 & 10 & 2.4845 & 2.5155 & 0.90 \\
\hline Model C & 9 & 47 & 32 & 8 & 2.4063 & 2.5937 & 0.78 \\
\hline Model D & 5 & 8 & 9 & 74 & 3.5833 & 1.4167 & 0.85 \\
\hline
\end{tabular}

\subsubsection{LINEAR REGRESSION MODELS}

In order to study the relationship between technical knowledge and price-perceived quality, the technical scores were tabulated for each respondent as the independent variable in a simple and multiple linear regression model with its corresponding price level (independent variable) and perceived quality (dependent variable). 
Once the data was collected, linear regression models were developed to study the relationship between technical knowledge and price-perceived quality. Since normally priceperceived quality behaves in a monotonically increasing manner, a linear model was first developed to observe the relationship between price and quality in an industrial setting. Table 4-8 contains the regression statistics that were used in the analysis of price and quality.

Given:

$$
\begin{aligned}
& \mathrm{Y}=\text { Perceived Quality (Dependent Variable) } \\
& \mathrm{X}=\text { Price (Independent Variable) }
\end{aligned}
$$

Table 4-8 Price-Perceived Quality Regression Model

$$
\text { Regression Statistics }
$$

\begin{tabular}{|c|c|c|c|c|c|}
\hline & $d f$ & $S S$ & $M S$ & Fobserved & $F$ critical \\
\hline Regression & 1 & 0.64 & 0.6417 & 0.691577848 & 3.96 \\
\hline Residual & 104 & 96.5 & 0.92788 & & \\
\hline Total & 105 & 97.1 & & & \\
\hline
\end{tabular}

\begin{tabular}{lr}
\hline R Square & 0.0066 \\
Standard Error & 0.9633 \\
Observations & 106 \\
\hline
\end{tabular}

ANOVA

\begin{tabular}{lcrrr}
\hline & Coefficients & \multicolumn{1}{c}{$\begin{array}{c}\text { Standard } \\
\text { Error }\end{array}$} & $\begin{array}{c}\text { t-Stat } \\
\text { observed }\end{array}$ & t-Stat critical \\
\hline Intercept & 1.3514 & 2.45 & 0.55176 & -259.6 \\
$\begin{array}{l}\text { X Variable 1 }= \\
\text { Price }\end{array}$ & 0.0008 & .00096 & 0.83161 & \\
\hline
\end{tabular}




$$
\text { Model: } \mathrm{Y}=.0008(\mathrm{X})+1.3514
$$

Table 4-9 Results of Hypotheses Test on Price Coefficient (Simple Regression)

\begin{tabular}{|c|c|c|}
\hline Step & Name & Values \\
\hline 1 & Hypothesis & $\begin{array}{l}\mathrm{H}_{0}: \beta \geq .25 \\
\mathrm{H}_{1}: \beta<.25\end{array}$ \\
\hline 2 & Significance Level & $\alpha=.05$ \\
\hline 3 & Critical Region & $\mathrm{t}_{104,05 \text { (critical) }}=1.6645$ \\
\hline 4 & Value of Test Statistic & $\mathrm{t}_{\text {(observed) }}=-259.6$ \\
\hline 5 & Rejection Region & $t_{\text {(observed) }}<-t_{\text {(critical) }}$ \\
\hline 6 & Results & Reject $\mathrm{H}_{0}$ \\
\hline * & Coefficient ofDetermination & $\mathrm{R}^{2}=.0066$ \\
\hline
\end{tabular}

Hypothesis tests on the price coefficient were performed by following the steps in Table 4-9. The null hypothesis states that there is a direct relationship between price and quality, whereas the alternative hypothesis states that there is no direct relationship between price and quality. The critical region was obtained from the Student's $t$ distribution using 104 degrees of freedom and a significance level of .05. The $t_{\text {(observed) }}$ was calculated as -259.6 . Since $t_{\text {(observed) }}<-t_{104,05}$, we reject the null hypotheses and conclude that there is no linear relationship between price and quality. As observed, the sample coefficient of determination, or $\mathrm{R}^{2}$, is .006 which indicated a weak linear relationship between price and perceived quality. This statement was supported by the $t$ statistical test. 
It is hypothesized that technical knowledge will make price-perceived quality lose its significance. After performing the multiple regression analysis, the following model was developed. Table 4-10 contains the regression statistics that were used in the analysis of technical knowledge and price-perceived quality.

Given:

$$
\begin{aligned}
& \mathrm{Y}=\text { Perceived Quality (Dependent Variable) } \\
& \mathrm{X}_{1}=\text { Price (Independent Variable) } \\
& \mathrm{X}_{2}=\text { Scores (Independent Variable) }
\end{aligned}
$$

Table 4-10 Technical Knowledge Regression Model Statistics

Regression Statistics

R Square

0.1083

Standard Error

0.9171

Observations

\begin{tabular}{|c|c|c|c|c|c|}
\hline & $d f$ & $S S$ & $M S$ & Fobserved & $F$ critical \\
\hline Regression & 2 & 10.5 & 5.25959 & 6.254014879 & 3.11 \\
\hline Residual & 103 & 86.6 & 0.84099 & & \\
\hline \multirow[t]{2}{*}{ Total } & 105 & 97.1 & & & \\
\hline & Coefficients & $\begin{array}{l}\text { Standard } \\
\text { Error }\end{array}$ & $t$ Stat & $t$-Stat critical & \\
\hline Intercept & 0.2998 & 2.35 & 0.12748 & & \\
\hline $\begin{array}{l}\mathrm{X} \text { Variable } 1= \\
\text { Price }\end{array}$ & 0.0007 & 0 & 0.73506 & 1.6645 & \\
\hline $\begin{array}{l}X \text { Variable } 2= \\
\text { Score }\end{array}$ & 0.02 & 0.01 & 3.4271 & 1.6645 & \\
\hline
\end{tabular}

106

ANOVA 
Hypothesis Tests of Significance of the Regression:

$$
\text { Model: } Y=.0007\left(X_{1}\right)+.02\left(X_{2}\right)+.2998
$$

Before testing each variable separately, we tested the significance of the relationship. This test told us that one of the variables was significantly different from zero. Since, we found that at least one predictor was significant, we also tested the hypothesis for each regression coefficient separately.

Table 4-11 Results of Hypothesis Test on the Regression Model

\begin{tabular}{|l|l|l|}
\hline Step & Name & Values \\
\hline 1 & Hypothesis & $\begin{array}{l}\mathrm{H}_{0}: \beta=0 \\
\mathrm{H}_{1}: \beta \neq 0\end{array}$ \\
\hline 2 & Significance Level & $\alpha=.05$ \\
\hline 3 & Critical Region & $\mathrm{F}_{(\text {critical) }}=3.11$ \\
\hline 4 & Value of Test Statistic & $\mathrm{F}_{(\text {observed) }}=6.25$ \\
\hline 5 & Rejection Region & $\mathrm{F}_{(\text {observed })}>\mathrm{F}_{\text {(citical) }}$ \\
\hline 6 & Results & ${\mathrm{Reject} \mathrm{H}_{0}}$ \\
\hline$*$ & Coefficient of Determination & $\mathrm{R}^{2}=.1083$ \\
\hline
\end{tabular}

Hypothesis tests on the regression model were performed by following the steps in Table 4-11. The null hypothesis states neither price or scores is a significant predictor of quality, wheras, the alternative hypothesis states that either price or scores is a significance predictor of quality. The critical region was defined by $F_{v l, v 2, \alpha}$ with vl number of variables (2), v2 degrees of freedom (103), and $\alpha$ significance level (.05). $F_{\text {(critical) }}$ was 3.11 . The 
$F_{\text {(observed) }}$ was calculated as 6.25. Since $F_{\text {(observed) }} 6.254014879$ is greater than $\mathrm{F}_{\text {(critical) }}$ 3.11, we rejected $\mathrm{H}_{0}$. Therefore, we were $95 \%$ sure that at least one of the variables is significant. Now, we proceeded to test the significance of each variable. But since the coefficient of determination, or $\mathrm{R}^{2}$, is .1083 which indicated that technical knowledge and price-perceived quality were highly uncorrelated, the $t$ statistics were used to test the hypothesis on the regression coefficients.

Hypothesis Tests on the Regression Coefficients

Price Coefficient:

Table 4-12 Results of Hypothesis Test on Price Coefficient (Multiple Regression)

\begin{tabular}{|l|l|l|}
\hline Step & Name & Values \\
\hline 1 & Hypothesis & $\begin{array}{l}\mathrm{H}_{0}: \beta \geq .25 \\
\mathrm{H}_{1}: \beta<.25\end{array}$ \\
\hline 2 & Significance Level & $\alpha=.05$ \\
\hline 3 & Critical Region & $\mathrm{t}_{104,05 \text { (critical) }}=1.6645$ \\
\hline 4 & Value of Test Statistic & $\mathrm{t}_{\text {(oberved) }}=-262.4$ \\
\hline 5 & Rejection Region & $\mathrm{t}_{\text {(oberved) }}<-\mathrm{t}_{\text {(ritical) }}$ \\
\hline 6 & Results & Reject $\mathrm{H}_{0}$ \\
\hline
\end{tabular}

Since $t_{\text {(observed). }}-262.4$ is less than $-t(1.6645)$, we rejected $\mathrm{H}_{0}$ which stated that there is no linear relationship between price and quality. 
Technical Knowledge Coefficient:

Table 4-13 Results of Hypothesis Test on Technical Knowledge Coefficient

\begin{tabular}{|l|l|l|}
\hline Step & Name & Values \\
\hline 1 & Hypothesis & $\begin{array}{l}\mathrm{H}_{0}: \beta=.25 \\
\mathrm{H}_{1}: \beta<.25\end{array}$ \\
\hline 2 & Significance Level & $\alpha=.05$ \\
\hline 3 & Critical Region & $\mathrm{t}_{104,05 \text { (critical) }}=1.6645$ \\
\hline 4 & Value of Test Statistic & $\mathrm{t}_{\text {(observed) }}=-39.42$ \\
\hline 5 & Rejection Region & $\mathrm{t}_{\text {(observed) }}<-\mathrm{t}_{\text {(critical) }}$ \\
\hline 6 & Results & Reject $\mathrm{H}_{0}$ \\
\hline
\end{tabular}

Since $t_{\text {(oberved) }}-39.42$ is less than $-t_{\text {(critical) }} 1.6645$, we rejected $\mathrm{H}_{0}$ which stated that there is no linear relationship between technical knowledge (scores) and quality.

\subsubsection{GRAPHICAL ASSESSMENT OF TECHNICAL KNOWLEDGE}

Since the analysis of both linear regression models indicate that a weak linear relationship between price and perceived quality, and technical knowledge and price-perceived quality, a graphical assessment of the scores was performed using the collected data in Table 4-14. Table 4-14 is the summary of the mean quality rating per technical knowledge level for each model. 
Table 4-14 Mean Quality Rating per Knowledge Level

\begin{tabular}{|c|c|c|c|c|}
\hline \multicolumn{2}{|c|}{ Model B } & \multicolumn{2}{|c|}{ Model A Model } & \multirow{2}{*}{ Model } \\
\hline TOTAL SCORE & 2400 & 2500 & 2600 & \\
\hline \multicolumn{5}{|c|}{ Perceived Quality } \\
\hline 24.14 & 1.00 & 2.00 & 4.00 & 3.00 \\
\hline 34.48 & 3.00 & 3.00 & 2.00 & 2.00 \\
\hline 41.38 & 3.00 & 2.67 & 2.00 & 2.33 \\
\hline 44.83 & 3.00 & 3.33 & 1.00 & 2.67 \\
\hline 48.28 & 2.00 & 4.00 & 1.00 & 3.00 \\
\hline 51.72 & 2.38 & 3.38 & 1.88 & 2.38 \\
\hline 55.17 & 2.50 & 3.75 & 1.00 & 2.75 \\
\hline 58.62 & 2.86 & 2.71 & 1.71 & 2.71 \\
\hline 62.07 & 2.88 & 3.00 & 1.88 & 2.25 \\
\hline 65.52 & 2.43 & 3.29 & 1.43 & 2.86 \\
\hline 68.97 & 1.78 & 3.89 & 1.67 & 2.67 \\
\hline 72.41 & 2.38 & 4.00 & 1.13 & 2.50 \\
\hline 75.86 & 3.00 & 3.60 & 1.00 & 2.40 \\
\hline 79.31 & 2.75 & 3.50 & 1.00 & 2.75 \\
\hline 82.76 & 2.33 & 3.83 & 1.33 & 2.50 \\
\hline 86.21 & 2.40 & 4.00 & 1.00 & 2.60 \\
\hline 89.66 & 2.14 & 4.00 & 1.14 & 2.71 \\
\hline 93.10 & 3.00 & 3.00 & 1.00 & 3.00 \\
\hline 96.55 & 2.00 & 4.00 & 1.00 & 3.00 \\
\hline 100.00 & 2.00 & 4.00 & 1.00 & 3.00 \\
\hline
\end{tabular}

Before the study questionnaire was distributed to the respondents, the true rankings of each model had to be established in order to be able to assess the price-perceived quality effect in an industrial setting. Model A had a true quality ranking of 4, which was the highest rank. Model $\mathrm{C}$ had a true ranking of 3 , which was the 2 nd highest rank. Model $\mathrm{B}$ had a true ranking of 2, which was the 3 rd highest ranking. Model D had a true ranking of 1 , which was the lowest ranking.

Figure 4-6a and Figure 4-6b depicts the relationship that exists between the level of technical knowledge and the price-perceived quality effect in an industrial setting. The 
minimum score, the median score, and the maximum score were used to illustrate the relationships.

Figure 4-6a Level of Technical Knowledge and Price-Perceived Quality Effect

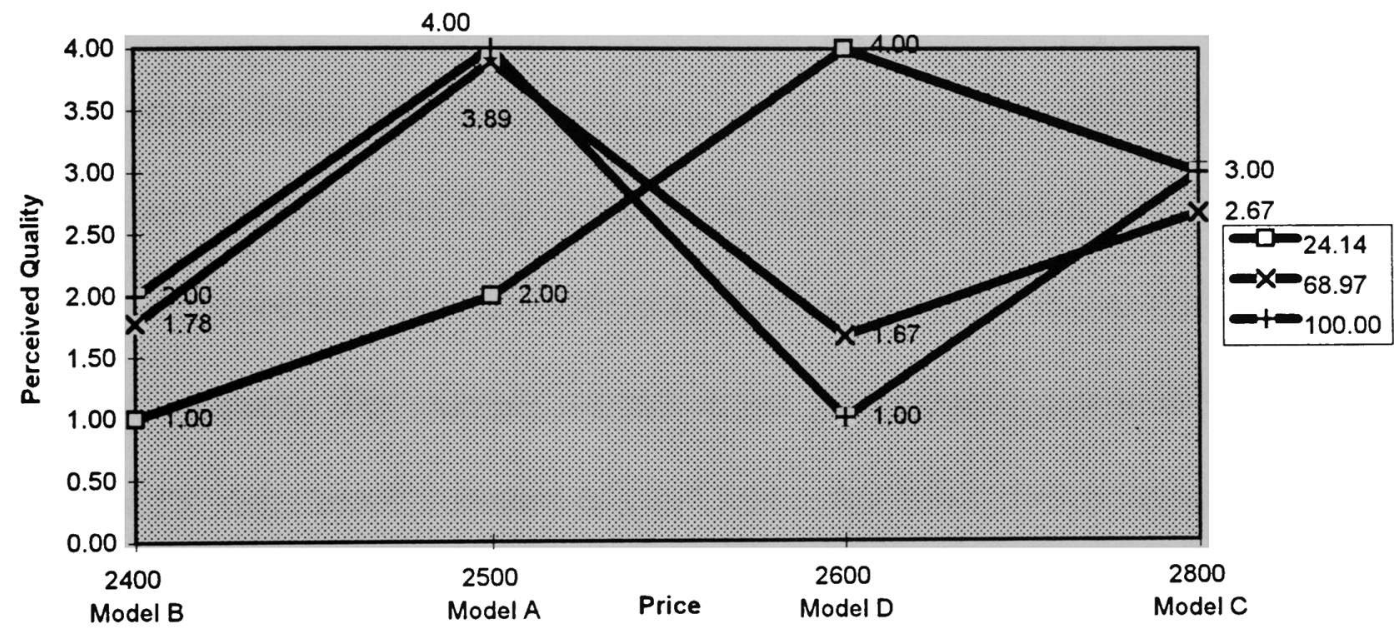

Figure 4-6b Level of Technical Knowledge and Price-Perceived Quality Effect

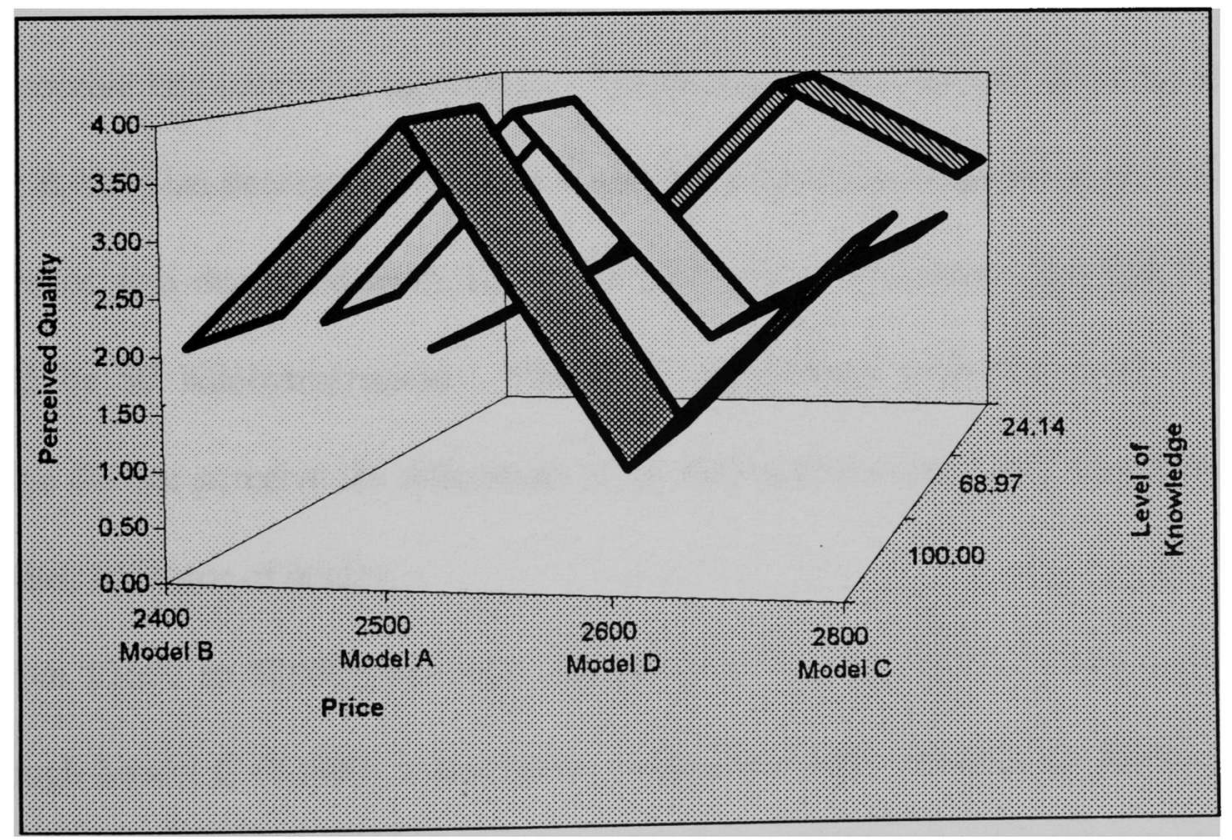


The minimum average score of 24.14 was used to show the relationship that exists between low level of technical knowledge and price-perceived quality in an industrial setting. As shown in Figure 4-6a and Figure 4-6b, the relationship between technical knowledge and price-perceived quality effect was found to be almost linear. Therefore, when the respondents had a low level of technical knowledge, price became an indicator of quality.

As shown on Figure 4-6a and Figure 4-6b, as price increase from $\$ 2400$ to $\$ 2600$, the perceived quality rating increased from 1 to 4 . From $\$ 2400$ to $\$ 2500$ price level, the perceived quality rating increased from 1 to 2 . The respondents were willing to pay $\$ 100$ to receive better computer features. For example, the respondent would have received $86 \mathrm{MB}$ more of Hard Drive, a 15" color monitor instead of a 14", better resolution, 50 kilobytes/second more of CD-ROM speed, and multiple floppy drives.

From $\$ 2500$ to $\$ 2600$ price level, the perceived-quality rating increased from 2 to 4 even though Model $\mathrm{D}$ is the worst quality computer. The respondents were willing to pay $\$ 100$ more to receive less computer capabilities. The microprocessor's speed decrease from 66 to $33 \mathrm{MHz}$, RAM Size decreased from 8 to $4 \mathrm{MB}$, Hard Drive Size decreased from 426 to 210 MB, monitor size decreased from 15" to 14 ", resolution decreased, and CD-ROM speed decreased by 50 Kilobytes/second. Therefore, respondents with low levels of technical knowledge did not perceive the differences in the technical attributes and, therefore, relied on price as their indicator of quality.

From $\$ 2600$ to $\$ 2800$ price level, the perceived-quality rating decreased from 4 to 3 even though Model C ( $\$ 2800)$ was a better quality computer. Maybe the $\$ 2800$ price level 
became a budget constraint and, therefore, Model D (\$2600) became the upper limit. In this case, the respondents were not willing to pay an extra $\$ 200$.

The median score of 68.97 was used to show the relationship that exists between a moderate level of technical knowledge and price-perceived quality in an industrial setting. As shown in Figure 4-6a and Figure 4-6b, the relationship between technical knowledge and priceperceived quality effect was found to be nonlinear.

As shown on the graph, as price increased from $\$ 2400$ to $\$ 2500$, the perceived quality rating increased from 1.78 to 3.89 . The respondents were willing to pay $\$ 100$ more to receive better computer features: $86 \mathrm{MB}$ more of Hard Drive, a 15" color monitor instead of a 14", better resolution, 50 Kilobytes/second more of CD-ROM speed, and multiple floppy drives. An industrial buyer with mid technical knowledge level could better distinguish the differences of the computer components; therefore, he/she can better judge the quality for a specified computer model.

From $\$ 2500$ to $\$ 2600$ price level, the perceived-quality rating decreased from 3.89 to 1.67. The respondents were not willing to pay $\$ 100$ more to receive less computer capabilities. The microprocessor's speed decrease from 66 to $33 \mathrm{MHz}$, RAM Size decreased from 8 to 4 MB, Hard Drive Size decreased from 426 to 210 MB, monitor size decreased from 15" to 14", resolution decreased, and CD-ROM speed decreased by 50 Kilobytes/second

From $\$ 2600$ to $\$ 2800$ price level, the perceived-quality rating increased from 1.67 to 2.67. In this case, the respondent was willing to pay an extra $\$ 200$ in exchange for better features. 
The very knowledgeable respondents buying behavior was very similar to the respondents with a mid level of technical knowledge. But in judging the four models, the perceived quality ratings were the most extreme. When judging a model, the very knowledgeable were better able to distinguish the differences in quality attributes as opposed to the respondents who possessed a moderate level of knowledge.

From $\$ 2400$ to $\$ 2500$, the mean quality rating went from 2.00 to 4.00 . They were willing to pay the additional $\$ 100$ to receive the extra benefits.

From $\$ 2500$ to $\$ 2600$, the mean quality rating declined from 4 to 1 . They were not willing to pay $\$ 100$ for less capabilities, the same as the mid level person respondents. As shown in the graph, the respondents with a high level of technical knowledge perceived a difference in quality of 3 between Model $\mathrm{A}(\$ 2500)$ and Model D $(\$ 2600)$. On the other hand, the respondents with mid level of technical knowledge perceived a difference of 2.22 between Model A and Model D. The respondents with mid level of technical knowledge were less able to perceive the differences in quality levels because of their lower level of knowledge. For example, they scored Model D with a higher quality level of 1.67 unlike the knowledgeable who scored Model D as 1.

From $\$ 2600$ to 2800 , the respondents were willing to spend $\$ 200$ more for added benefits, like the mid knowledgeable respondents. But again, the more knowledgeable respondents perceived the difference in quality of 2 between Model D (\$2600) and Model $\mathrm{C}(\$ 2800)$ while the mid knowledgeable perceived only a difference of 1 between the same models. 
Figure 4-7 and 4-8 depict the price-perceived quality pattern as technical knowledge increases. The transition from linear to nonlinear was random. Further research is needed in this area. As described earlier (Figure 4-6a and Figure 4-6b), the respondents with low level of technical knowledge used price as an indicator of quality. This behavior was almost linear. As priced increased, the quality level increased even though Model D (\$2600) was definitely the worst quality computer system. As technical knowledge increased, the behavior became nonlinear. On the extreme end, a respondents with a high level of technical knowledge were able to rank the computer models more effectively by using their technical expertise to differentiate among computer components and then ranking the computer models accordingly: Model A (\$2500) was ranked as the best, Model C $(\$ 2800)$ as the second best, Model B $(\$ 2400)$ as the third best, and Model D $(\$ 2600)$ as the worst. Therefore, one can conclude that in an industrial setting, price was not used as an indicator of quality. At the mid point, the respondents with mid level of technical knowledge also ranked the models very similar to the very knowledgeable respondents(nonlinear behavior). But they were less able than the knowledgeable respondents in perceiving the difference in quality among the four computer models. 
Figure 4-7 Price-Perceived Quality Pattern based on Technical Knowledge

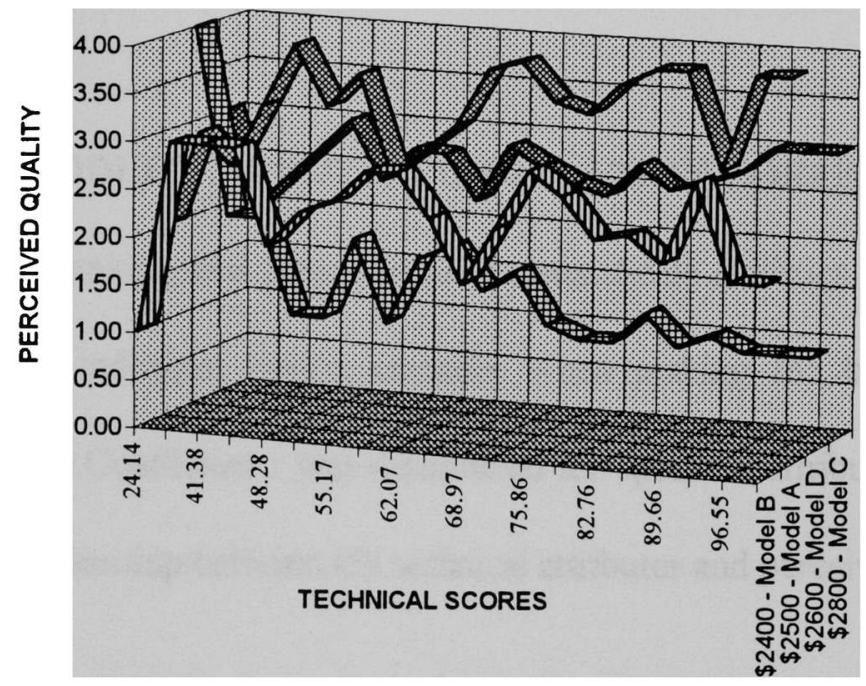

PRICE

Figure 4-8 Technical Knowledge vs Perceived Quality

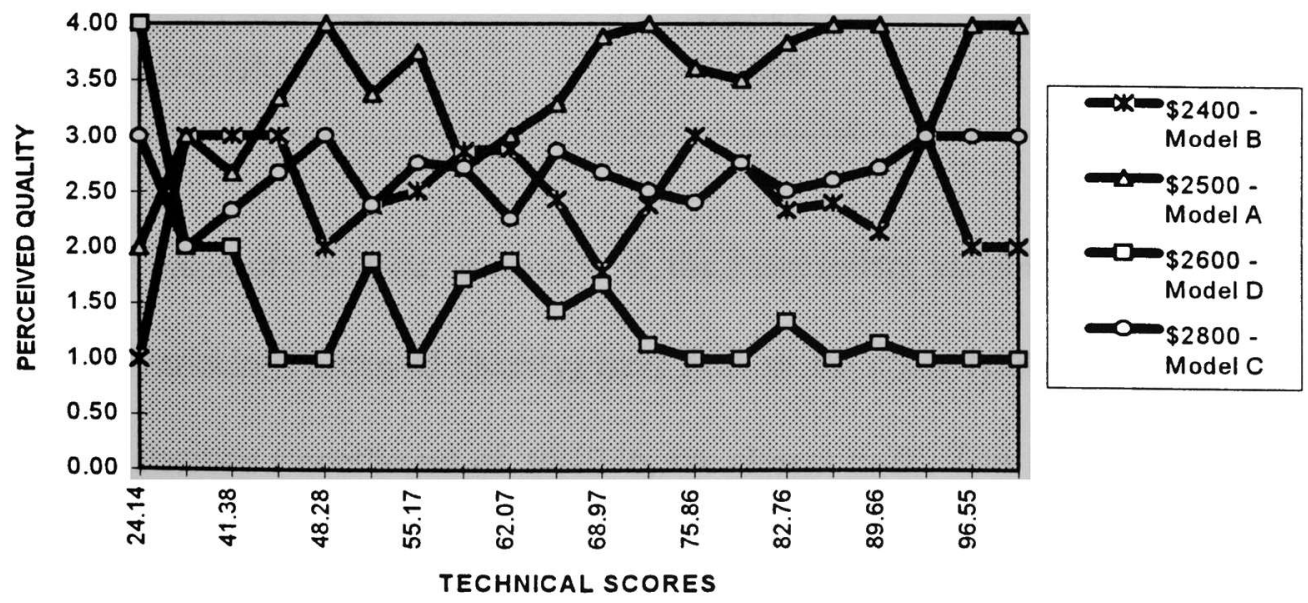


Having established the relationship between technical knowledge and price-perceived quality effect, we continued to determine the strength and direction of the relationship between technical attributes and perceived quality.

\subsubsection{PEARSON PRODUCT MOMENT CORRELATION COEFFICIENT}

The Attribute Ranking and Semantic Differential Scale statistics determined the most salient attributes that industrial buyers consider when making the best quality purchase decision. The Pearson Coefficient $r$ was determined for specified attributes in order to study the strength of the relationship between the technical attributes and perceived quality.

Table 4-15 Technical Attributes Correlated with Perceived Quality

\begin{tabular}{lcc}
\hline $\begin{array}{l}\text { Attributes Correlated With } \\
\text { Perceived Quality }\end{array}$ & Pearson r & Significance \\
\hline 1. Price & .081276 & no \\
2. Processing Speed & .554740 & yes \\
3. RAM Size & .554740 & yes \\
4. Hard Drive Size & .948582 & yes \\
5. CD-ROM Speed & .932148 & yes \\
\hline
\end{tabular}

When the value of $r$ is linear or equal to 0 , the independent variable (technical attributes) and dependent variable (Perceived Quality) have little or no linear relationship. Attribute \#1 (Price) has the Pearson $r$ coefficient of .081276 , the closest to 0 . This indicates a moderately weak direct relationship with quality. Price and perceived quality possess the least amount of 
linear relationship. This demonstrates that Price and Perceived Quality behave in a different manner than Price Perceived Quality Effect found in a consumer market.

Processing Speed and RAM Size have a positive effect on perceived quality, but at the same time they possess a moderately strong linear relationship with respect to quality. In addition, Hard Drive Size and CD-ROM have a positive effect on quality and possess a strong relationship with perceived quality. This output agrees with the results from the attribute ranking and semantic differential scale statistics where the subjects found these attributes important in the purchase of the best quality computer system.

When more key technical information is present during the industrial purchase, technical quality attributes will guide the industrial buyer to better evaluate the alternatives and information as the industrial buyer's technical knowledge increases. Consequently, the industrial buyer will make the best overall quality decision 


\section{CHAPTER 5: CONCLUSION AND FURTHER RESEARCH}

The goal of this study was to determine how technical knowledge moderates the priceperceived quality effect in an industrial setting. This study examined the relationship between an industrial buyer's level of technical knowledge and price-perceived quality effect. It was hypothesized that the price-perceived quality effect will lose its significance in an industrial setting as technical knowledge increases.

Although limited in scope, this study indicates that the relationship between technical knowledge and price-perceived quality effect, in an industrial setting, seems to move from an almost linear to a nonlinear behavior as technical knowledge increases. Results of this effort, for the specific experiment, include:

1. Attribute Ranking Analyses found price loses its significance as a quality indicator when other quality attributes are present. These results helped strengthen the hypothesis that the price-perceived quality effect will lose its significance in an industrial setting.

2. It was noted that the performance factors, such as processing speed, RAM size, hard drive size, CD-ROM speed, were salient attributes over price that helped subjects to form their perceptions about each one of the product models. This outcome also helps us to support the hypothesis.

3. A Price-Perceived Quality Simple Regression Model detected no direct relationship between price and perceived quality. In addition, correlation analysis techniques 
(Coefficient of Determination) yielded that the relationship between price and quality is weak, which led to the conclusion that there is evidence of no relationship between the two. Therefore, the study continued investigating how knowledge (independent variable) moderated the price-perceived quality effect.

4. The Technical Knowledge Multiple Regression Model detected that technical knowledge and price did not have a linear relationship with quality. A graphical assessment of this relationship found that price-perceived quality effect moves from an almost linear to a nonlinear one as technical knowledge increases. However, the transition from linear to nonlinear seems to be random. These findings validate the hypothesis that price-perceived quality will lose its effect as technical knowledge increases.

5. The Pearson Product Moment Correlation Coefficient found that the performance factors such as processing speed, RAM size, hard drive size, and CD-ROM speed, possess very strong and positive correlation with quality. These technical attributes were considered strong indicators of quality by the respondents. However, price inicated a moderately weak positive relationship with quality. Again, these results give credence to the hypothesis that the price-perceived quality effect will lose its significance. Even though further research is needed to validate these results using other products, it might be expected that the technical attributes of other products will have a have stronger effect on quality than price.

Throughout this study, we have established reasonable foundations to believe that the price-perceived quality effect does not behave in a positive linear manner as it does in consumer 
oriented environments. Instead, as the level of technical knowledge increases, the priceperceived quality effect moves from an almost linear to nonlinear one. Therefore, we suggest that the hypothesis (price-perceived quality effect will lose its significance in an industrial setting as technical knowledge increases) is indeed true. However, further studies are needed to generalize the findings of this specific experiment to other domains. The following extensions are suggested:

1. Since the hypothesis is tested using engineers in a university setting, it is recommended that the price-perceived quality effect be examined using engineers in a true industrial setting.

2. Industrial, Mechanical, and Electrical Engineers are suspected to be more involved in an industrial purchase than any other type of engineer due to the nature of the fields. Industrial Engineers being the most probable to be involved in this type of purchase, Mechanical Engineers second highest, and Electrical Engineers third highest. Therefore, careful attention should also be given to a good representation of industrial buyers as well as a large sample. For example, in a sample of size, $40 \%$ should be Industrial Engineers, 35\% Mechanical Engineers, and 25\% Electrical Engineers. These percentages are an empirical guide to the composition of any sample. It is based on the intrinsic nature of the type of engineers that engage in industrial purchasing. As such, these percentages simply state that there should be a 4:3:2 ratio of these three classes of engineers.

3. In addition, in order to determine if the relationship between technical knowledge and price-perceived quality holds true for different industrial products in different industries, a range of industrial products should be utilized in setting up an experiment to study this 
relationship. For example, a group of products common to various plants in a textile industry should be tested. The following are some example of industries that can be tested: Medical, Petrochemical , Chemical, Paper, Plastics, Artificial Intelligence, and Electronics.

4. Some design weaknesses were found in the measurement instrument. The measurement instrument needs to be enhanced by adding key technical descriptions to the quality attributes. Before administering the questionnaire to the selected sample, it is also recommended that the design instrument be pretested in order to determine potential design errors which can decrease the accuracy of the results.

Despite its shortcomings, this study demonstrates the importance of further research on this topic because the results could be applied to the following areas:

1. Development of Pricing Strategies: Industrial marketers need to develop different pricing strategies for various markets. If the industrial marketer is dealing with a knowledgeable industrial buyer, the industrial marketer should emphasize more on technical performances of the product because he/she knows that the industrial buyer will be able to detect the quality attributes of the product and be willing to spend extra dollars to receive extra benefits in the form of product quality. However, if the industrial buyer is not knowledgeable, the industrial marketer may use price as the primary key to attract customers.

2. Industrial Purchase Training: From the results, it was detected that even with a small amount of product knowledge, the industrial buyer is able to make better decisions. 
Therefore, the organization's industrial engineers should identify the attributes for a specified product that are important in making a quality industrial purchase. Once all this information has been gathered, the industrial engineers should set up training classes that educate the industrial purchasers about the key ingredients of making a quality decision.

3. Industrial Selling: Results show that the subjects with higher level of technical knowledge made the best quality decisions. These results can be applied to industrial selling because industrial sellers must first determine and define the expectations of the industrial buyers in order to satisfy those expectations and be successful in the long run (Scheuing, 1989). Consequently, a close customer-supplier relationship will develop. The focal point of the relationship is the account sales representative, who continuously searches and probes to identify evolving needs and requirements of an organization, and coordinates sales-service support and the flow of product to suit the dynamics of the industrial customer situation. Therefore, the industrial seller should train their industrial customers and provide them with the technical information and specifications necessary in order for the industrial buyer to make an informed quality decision. 


\section{REFERENCES}

Andrews, I. R. and Valenzie, E. R. (1970). The Relationship Between Price and Blind Rated Quality for Margarines and Butters. Journal of marketing Research. 7, 393-395.

Andrews, I. R. and Valenzie, E. R. (1971). Combining Price, Brand and Store Cues to Form an Impression of Product Quality. Proceedings of the American Psychological Association, 649-650.

Assael, H. (1987). Consumer Behavior and Marketing Action, Boston: Kent Publishing Co.

Bettman, J. R. (1973). Perceived Price and Product Perceptual Variables. Journal of Marketing Research, 10, 100-102.

Celsi, R. L., and Olsen, J. C. (1988). The Role of Involvement in Attention and Comprehensive Processes. Journal of Consumer Research, 15, 210-224.

Cimbalo, R. S. and Webdale, A. M., (1973). Effects of Price Information on Consumer-Rated Quality. Proceedings of American Psychological Association, 649-650.

Cox, D. G. (1962). The Measurement of Information Value: A Study in Consumer DecisionMaking. Emerging Concepts in Marketing, 413-421.

Darby, M. R., and Karni, E. (1973). Free Competition and the Optimal Amount of Fraud. Journal of Law and Economics, 16 , 67-68.

Davis, L. L. (1985). Effects of Physical Quality and Brand Labeling on Clothing Quality. Perceptual and Motor Skills, 61, 671-677. 
Deering, B. J. and Jacoby, J. (1972). Price Intervals and Individual Price Limits as Determinants of Product Evaluation and Selection. In M. Venkatesen (Ed.), Proceedings of the Third Annual Conference of the Association for Consumer Research.

Downing, D. and Covington, M. (1992). Dictionary of Computer Terms, New York: Barron's Educational Series, Inc.

Enis, B. and Stafford, J. E. (1969). Influence of Price and Store Information Upon Product Quality Perception. Southern Journal of Business, 4, 90-99.

Etgar, M., and Malhotra, N. K. (1981). Determinants of Price Dependency: Personal and Perceptual Factors. Journal of Consumer Research, $\underline{8}, 217-221$.

Erickson, G. M., and Johansson, J. K. (1985). The Role of Price in Multi-Attribute Product Evaluations. Journal of Consumer Research, 12, 195-199.

Freedman, A. (1991). The Computer Glossary, Pennsylvania: The Computer Language Company, Inc.

French, N. D., Williams, J. J., and Chance, W. A. (1972). A Shopping Experiment on Price Quality Relationships. Journal of Retailing, $\underline{48}, 16$.

Gardner, D. M. (1970). An Experiment Investigation of the Price-Quality Relationships. Journal of Retailing, $\underline{46}, 24-41$.

Gardner , D. M. (1971). Is There a Generalized Price-Quality Relationship? Journal of Marketing Research, $\underline{8}, 241-243$. 
Jacoby, J. and Olson, J. C. (1985). Perceived Quality - How Consumers View Stores and Merchandise, MA: D. C. Heath and Company.

Jacoby, J., Olson J. C., and Haddock, R. A. (1971). Price, Brand Name and Product Composition Characteristics as Determinants of Perceived Quality. Journal of Applied Psychology, 55, 577.

Jon, W.-J., and Jolibert, A. J. P. (1983). Revealed versus Hidden Attributes as Determinants of Perceived Product Quality. Journal of Economic Psychology, 4, 263-272.

Kotler, P. (1988). Marketing Management: Analysis, Planning, Implementation, and Control, New Jersey: Prentice-Hall, Inc.

Lambert, Z. V. (1970). Product Perception: An Important Variable in Pricing Strategy. Journal of Marketing, $\underline{34}, 68-71$.

Lambert, Z. V. (1972). Price and Choice Behavior. Journal of Marketing Research, $\underline{9}, 35-40$.

Lauridsen, M. L. (1973). The Relationship Between Price and Perceived Quality: An Experimental Study. Marketing Communication, 2 , 1-12.

Leavitt, H. J. (1954). A Note of Some Experimental Findings about the Meaning of Price. Journal of Business, 27, 205-210.

Marks, L. J. and Olson, J. C. (1981). Toward a Cognitive Structure Conceptualization of Product Familiarity. Advances of Consumer Research, $\underline{8}, 145-150$. 
Mendenhall, W. and Sincitt, T. (1992). Statistics for Engineering and the Sciences, Dellen Publishing Co.; a Division of MacMillan Publishing Co.

McConnel, J. D. (1968). The Effect of Pricing in an Experimental Setting. Journal of Applied Psychology, 52, 331-334.

Monroe, K. B. (1973). Buyers' Subjective Perceptions of Price. Journal of Marketing $\underline{\text { Research, }}$ 10, 70-80.

Monroe, K. B. and Krishan, R. (1985). The Effect of Price on Subjective Product Evaluations. In J. Jacoby, J. C. Olsen (Eds.), Perceived Quality (pp. 209-232.) MA: D. C. Heath \& Company.

Moriarty, R. (1983). Industrial Buying Behavior: Concepts, Issues, and Applications, Massachusetts: D.C. Heath and Company.

Nelson, P. (1970). Information and Consumer Behavior. Journal of Political Economy, $\underline{78}$, 311-329.

Nelson, P. (1974). Advertising as Information. Journal of Political Economy, $\underline{81}, 729-754$.

Olson, J. C. (1972). Cue Utility of the Quality Perception Process: a Cognitive Model and an Empirical Test, unpublished doctoral dissertation, Purdue University.

Olson, J.C. (1973). Cue Properties of Price: Literature Review and Theoretical Considerations. paper presented at 83rd Annual Convention of the American Psychological Association. Montreal, Canada. 
Please circle your response to each of the following:

1. An accelerator board

(a) replaces the existing RAM with a higher performance RAM.

(b) is a video board with a CPU for handling video.

(c) increases the RAM which allows better access to ROM.

(d) don't know.

2. A bad sector is typically

(a) a segment of the disk storage that cannot be read or written due to a problem in the RAM.

(b) a segment of the disk storage that cannot be read due to a problem in the ROM.

(c) a segment of the disk storage that cannot be read or written due to a physical problem in the disk.

(d) don't know.

3. Which of the following microprocessors can process data more quickly, given that all microprocessors perform exactly the same set of instructions?
(a) Pentium processor
(b) Intel 80286 microprocessor
(c) Intel $80486 \mathrm{SX}$ microprocessor
(d) don't know.

4. CACHE is a place where

(a) major arithmetic operations are performed rather than using the CPU.

(b) data which is not frequently utilized is stored.

(c) data can be stored to avoid having to read the data from a slower device such as a disk.

(d) don't know.

5. Which of the following terms refer to the use of compact disks where the computer can save information once, can read that information, but cannot change it?
(a) CD-ROM
(b) WORM
(c) don't know.

6. A computer with a faster clock rate is able to perform more operations per second. Clock rate is measured in which of the following units?
(a) Megahertz
(b) Kilowatt-hour
(c) Seconds
(d) don't know.

7. CMOS RAM is a kind of memory that
(a) stores information about the configuration of the IBM PC's or equivalent processors.
(b) stores software programs.
(c) don't know. 
Olson, J. C. (1977). Price as an Information Cue: Effects of Product Evaluations. In A. G. Woodside, J. N. Shetyh, and P. D. Bennetts (Eds.), Consumer and Industrial Buying Behavior (pp. 267-286) New York: North Holland.

Olson, J. C. and Jacoby, J. (1972). Cue Utilization in the Quality Perception Process. In M. Venkatesen (Ed.), Proceedings of the Third Annual Conference of the Association for Consumer Research (pp. 167-179).

Parasuraman, A. (1986). Marketing Research, Massachusetts: Addison-Wesley Publishing Company, Inc.

Peterson, R. A. (1970). The Price-Perceived Quality Relationship: Experimental Evidence. Journal of Marketing Research, 7, 525-528.

Pincus, S. and Waters, L. K. (1975). Product Quality Ratings as a Function of Availability of Intrinsic Product Cues and Price Formation. Journal of Applied Psychology, 60, 280282.

Raju, P. S. (1977). Product Familiarity, Brand Name, and Price Influences on Product Evaluations. In W. D. Perreault, Jr. (Ed), Advances in Consumer Research (64-71) Association of Consumer Research.

Rao, Vithala (1971). Salience of Price in the Perception of Product Quality: A Multidimensional Measurement Approach. In Alvine, F. C. (Ed.), Proceedings in the American Marketing Association (pp 571-577). 
Rao, A. R., and Monroe, K. B. (1989). The Effect of Price, Brand Name, and Store Name on Buyers' Perception of Product Quality: An Integrative Review. Journal of Marketing $\underline{\text { Research, }}$ 26, 351-357.

Robinson, P. J., Faris, C. W., and Wind, P. (1967). Industrial Buying and Creative Marketing, Boston: Allyn \& Bacon.

Scheuing, E. E. (1989). Purchasing Management. New Jersey: Prentice-Hall, Inc.

Scitovsky, T. (1945). Some Consequences of the Habit of Judging Quality by Price. The Review of Economic Studies, 12, 100-105.

Shapiro, B. P. (1970). Price as a Communicator of Quality: An Experiment. In J. Jacoby, J. C. Olsen (Eds.), Perceived Quality (pp. 209-232.) MA: D. C. Heath \& Company.

Shapiro, B.P.(1972). The Pricing of Consumer Goods: Theory and Practice. In J. Jacoby, J. C. Olsen (Eds.), Perceived Quality (pp. 209-232.) MA: D. C. Heath \& Company.

Stafford, J. E., and Enis, B. M. (1969). The Price Quality Relationship: An Extension. Journal of Marketing Research, 6 , 456-548.

Steenkamp, J.-B. E. M. (1990). Conceptual Model of the Quality Perception Process. Journal of Business Research, 21, 309-333.

Szybillo, G. J. and Jacoby, J. (1974). Extrinsic Cues as Determinants of Perceived Product Quality. Journal of Applied Psychology, 59, 74-78. 
Valenzie, E. R. and Andrews, I. R. (1971). Effect of Price Information on Product Quality Ratings. Journal of Applied Psychology, 55, 87-91.

Valenzie, E. R. and Eldridge, L. (1973). Effect of Price Information, Composition Differences, Expertise and Rating Scales on Product Quality Rating. Proceedings American Psychological Association, 829-830.

Walters , C. G., and Bergiel, B. J. (1989). Consumer Behavior - a Decision Making Approach, Ohio: South-Western Publishing Co.

Wheatley, J. J., and Chiu, J. S. Y. (1977). The Effects of Price, Store Image and Product and Respondent Characteristics on Perceptions of Quality. Journal of Marketing Research, 14, 181-186.

Wheatley, J. J., Chiu, J. S. Y., and Goldman, A. (1981). Physical Quality, Price, and Perceptions of Product Quality: Implication for Retailers. Journal of Retailing, 57,100116. 
Appendix A

Questionnaire Tier 1 
8. CPU stands for
(a) Computer Processing Unit
(b) Central Procedures Unit
(c) Central Processing Unit
(d) don't know.
(e)

9. A modem

(a) stands for modulator demodulation.

(b) encodes and decodes data for transmission over a particular medium (i.e. telephone lines, fiber optics, or microwaves).

(c) don't know.

10. A mouse

(a) is a computer input device.

(b) is a computer output device.

(c) don't know.

11. Multimedia refers to
(a) visual information
(b) sound information
(c) the combination of visual and sound information.
(d) don't know.

12. Which of the following is a peripheral device?
(a) disk drives
(b) CPU
(c) RAM
(d) don't know.

13. RAM is an acronym for:
(a) Random Acquired Memory
(b) Random Access Memory
(c) Random Admittance Memory
(d) don't know.

14. ROM is an acronym for
(a) Random Operating Memory
(b) Random On-line Memory
(c) Read Only Memory
(d) don't know. 
15. Software

(a) refers to the programs that tell the computer what to do.

(b) refers to the actual physical machines that make up the computer.

(c) Word Processing, Spreadsheet, Database Management, and RAM are types of software.

(d) don't know.

16. Memory

(a) is a collection of ROM chips.

(b) affects the size and number of programs that can run at the same time.

(c) don't know.

17. CAM stands for

(a) Central Adapted Modulation

(b) Computer Aided Multiprocessing

(c) Computer Acquired Module

(d) Computer Aided Manufacturing

Please indicate your response by placing an " $\mathrm{X}$ " in the appropriate position.

1. AT (Advanced Technology) refers to the class of IBM PC's originally introduced in 1984 using the 80286 microprocessor and 16-bit data bus.

True False

2. Hardware consists of all the physical elements of the computer.

True False

3. CAD software can be run using a color/graphics adapter card with only suitable high resolution monitor.

True False

4. A microprocessor is a an integrated circuit containing an entire CPU on three chips. One chip contains the CPU. One chip is designated for the input devices and the other for the output devices.

True False

5. Memory is the runtime storage that is physically a collection of RAM chips.

True False

6. The major categories of memory chips are RAMs and ROMs.

True False

7. Disk speed and caching play a major role in the computer's actual performance.

True False 
8. Operating systems call the BIOS which is a set of detailed procedures for activating the peripheral devices connected to a computer.

True False

9. One byte is equal to eight bits.

True False

10. The coprocessor is a separate circuit used to speed up operations by handling some of the workload of ROM.

True False

11. DOS stands for Disk Operator System.

True False

12. A frame grabber takes image from video camera and digitizes it, creating a bit-map image. True False 
Multiple Choice:

1. B

2. C

3. $\mathrm{A}$

4. C

5. B

6. A

7. A

8. C

9. B

10. A

11. C

12. $\mathrm{A}$

13. B

14. C

15. A

16. B

17. D

\section{True/False:}

$\begin{array}{ll}\text { 1. } & \mathrm{T} \\ \text { 2. } & \mathrm{T} \\ \text { 3. } & \mathrm{T} \\ \text { 4. } & \mathrm{F} \\ \text { 5. } & \mathrm{T} \\ \text { 6. } & \mathrm{T} \\ \text { 7. } & \mathrm{T} \\ \text { 8. } & \mathrm{T} \\ \text { 9. } & \mathrm{T} \\ \text { 10. } & \mathrm{F} \\ \text { 11. } & \mathrm{F} \\ \text { 12. } & \mathrm{T}\end{array}$


Appendix B

Questionnaire Tier 2 


\section{PROBLEM RECOGNITION}

Company "XYZ" is interested in creating multimedia courseware. This courseware will be used for the company's training program. In order to develop this courseware, the company needs new equipment.

\section{GENERAL NEED DESCRIPTION}

A computer system capable of importing video and audio from a VCR to a hard drive and providing full editing of the video and audio then exporting back to VCR format. Multimedia software available on compact disks has already been purchased for this application.

You must purchase the best quality computer that meets the need of the company. Examine the four computer models (see attachment) and complete the questionnaire.

Rank the following attributes by placing a number (1-10) beside each attribute, in which 1 means the most important in making the final purchase, 2 is the second most important attribute, and so on:

Processing Speed
RAM Size
Hard Drive Size
Floppy Drive Size
Monitor Size
Monitor Resolution
CD-ROM Speed
Price
Video Card
Hardware Compatibility

Please list any other factor that you may consider when purchasing this new equipment. Please state its importance. 
Based on the computer descriptions, please provide your opinion of each model by placing an "X" in the appropriate column. (Please evaluate each model independently.)

\begin{tabular}{|c|c|c|c|}
\hline \\
\hline \multicolumn{4}{|c|}{ MODEL A } \\
\hline 1. & High processing speed & _:_:_:_____:_ & Low processing speed \\
\hline 2. & Small RAM & _:_:_:_:_:_- & Large RAM \\
\hline 3. & Large Hard Drive & _:_:_- & Small Hard Drive \\
\hline 4. & Single Disk Drive Assortment & - :_:_:_:- & Multiple Disk Drive Assortment \\
\hline 5. & Large Computer Monitor & - :- & Small Computer Monitor \\
\hline 6. & Low Resolution & _:_:_:_:_:_:_ & High Resolution \\
\hline 7. & High Speed CD-ROM & _:_:_:_:_:_:_ & Low Speed CD-ROM \\
\hline 8. & Low Prices & $-1-1$ & High Prices \\
\hline
\end{tabular}

\begin{tabular}{|ll}
\hline MODEL B \\
1. & High processing speed \\
2. & Small RAM \\
3. & Large Hard Drive \\
4. & Single Disk Drive Assortment \\
5. & Large Computer Monitor \\
6. & Low Resolution \\
7. & High Speed CD-ROM \\
8. & Low Prices \\
\hline
\end{tabular}

1234567

_:_:_:_:_:-_ Low processing speed

_:_:_:_:_-_ Large RAM

_:_:_:_:_- Small Hard Drive

:-_:-_:- Multiple Disk Drive Assortment

_:_:_:_:_:_ Small Computer Monitor

_:_:_:_:_-_ High Resolution

L_:_:- Low Speed CD-ROM

_:__:_:_:- High Prices

\begin{tabular}{|ll}
\hline MODEL C \\
1. & High processing speed \\
2. & Small RAM \\
3. & Large Hard Drive \\
4. & Single Disk Drive Assortment \\
5. & Large Computer Monitor \\
6. & Low Resolution \\
7. & High Speed CD-ROM \\
8. & Low Prices \\
\hline
\end{tabular}

1234567

-:-_:_:_:_-

- :-_:_:_:-

$\because:::::$

- - - - - - -

- ㄴ__:_:_:-

ㄴ._:_:_:- :-

$\therefore:-2:-:-$

- :-_:_:_:-

$\cdot \cdot \cdot \cdot \cdot$

Low processing speed

Large RAM

Small Hard Drive

Multiple Disk Drive Assortment

Small Computer Monitor

High Resolution

Low Speed CD-ROM

High Prices 
MODEL D

1. High processing speed

2. Small RAM

3. Large Hard Drive

4. Single Disk Drive Assortment

5. Large Computer Monitor

6. Low Resolution

7. High Speed CD-ROM

8. Low Prices

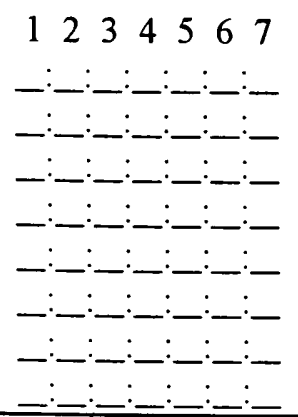

Low processing speed

Large RAM

Small Hard Drive

Multiple Disk Drive Assortment

Small Computer Monitor

High Resolution

Low Speed CD-ROM

High Prices

Please rank the models on a scale from 1 to $4(1=1$ st choice, $2=2$ nd choice, $3=3$ rd choice, $4=$ 4th choice).

Model A
Model B
Model C
Model D

Does the 1st choice meet all the needs of company "XYZ"? _ Y Yes _ No.

If you answered no, please explain.

You must purchase the best quality computer which meet the needs of the company. Which one will you purchase?

$\begin{array}{crr}\text { Model } & & \text { Price } \\ \text { A } & & 2,500 \\ \text { B } & & 2,400 \\ \text { C } & & 2,800 \\ \text { D } & & 2,600\end{array}$

I would prefer Model 


\section{BACKGROUND INFORMATION}

Please " $\sqrt{ }$ the appropriate categories.

1 University Professor

Graduate Student

Undergraduate Student

1st year of College

2nd year of College

3rd year of College

4th year of College

Other. Specify

2. Please indicate your field of study.

_ Mechanical Engineering

_ Industrial Engineering

- Civil Engineering

_Electrical Engineering

_ Computer Engineering

_Other. Please specify

3. Male

Female

4. Have you ever been involved in the purchase of a computer system for your personal use?

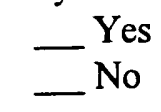

If "YES" when 1994 1993 1992

— Other. Please specify

5. Have you ever been involved in the purchase of a computer system at your work place?

$$
\begin{aligned}
& \begin{array}{l}
\text { Yes } \\
\text { - No }
\end{array} \\
& \text { If "YES" when _ } 1994 \\
& 1993 \\
& 1992 \\
& \text { Other. Please specify }
\end{aligned}
$$




\section{APPENDIX C}

Observations Technical Scores vs. Price-Perceived Quality 
Observations Technical Scores vs. Price-Perceived Quality

OBS. NO. BEST MODEL PRICE SCORE QUALITY

\begin{tabular}{|c|c|c|c|c|}
\hline 5 & 2 & 2400 & 34 & 2 \\
\hline 56 & 2 & 2400 & 34 & 2 \\
\hline 57 & 2 & 2400 & 41 & 2 \\
\hline 9 & 2 & 2400 & 45 & 2 \\
\hline 1 & 2 & 2400 & 52 & 2 \\
\hline 125 & 2 & 2400 & 52 & 2 \\
\hline 35 & 2 & 2400 & 55 & 2 \\
\hline 36 & 2 & 2400 & 59 & 2 \\
\hline 133 & 2 & 2400 & 59 & 2 \\
\hline 143 & 2 & 2400 & 59 & 2 \\
\hline 149 & 2 & 2400 & 59 & 2 \\
\hline 26 & 2 & 2400 & 62 & 2 \\
\hline 59 & 2 & 2400 & 62 & 2 \\
\hline 28 & 2 & 2400 & 66 & 2 \\
\hline 74 & 2 & 2400 & 66 & 2 \\
\hline 98 & 2 & 2400 & 69 & 2 \\
\hline 134 & 2 & 2400 & 76 & 2 \\
\hline 54 & 2 & 2400 & 79 & 2 \\
\hline 70 & 2 & 2400 & 79 & 2 \\
\hline 71 & 2 & 2400 & 79 & 2 \\
\hline 42 & 2 & 2400 & 83 & 2 \\
\hline 112 & 1 & 2500 & 41 & 4 \\
\hline 8 & 1 & 2500 & 45 & 4 \\
\hline 67 & 1 & 2500 & 45 & 4 \\
\hline 27 & 1 & 2500 & 48 & 4 \\
\hline 14 & 1 & 2500 & 52 & 4 \\
\hline 64 & 1 & 2500 & 52 & 4 \\
\hline 76 & 1 & 2500 & 52 & 4 \\
\hline 90 & 1 & 2500 & 52 & 4 \\
\hline 123 & 1 & 2500 & 52 & 4 \\
\hline 65 & 1 & 2500 & 55 & 4 \\
\hline 73 & 1 & 2500 & 55 & 4 \\
\hline 87 & 1 & 2500 & 55 & 4 \\
\hline 94 & 1 & 2500 & 55 & 4 \\
\hline 2 & 1 & 2500 & 59 & 4 \\
\hline 58 & 1 & 2500 & 59 & 4 \\
\hline 69 & 1 & 2500 & 59 & 4 \\
\hline 18 & 1 & 2500 & 62 & 4 \\
\hline 23 & 1 & 2500 & 62 & 4 \\
\hline 33 & 1 & 2500 & 62 & 4 \\
\hline 140 & 1 & 2500 & 62 & 4 \\
\hline 6 & 1 & 2500 & 66 & 4 \\
\hline 10 & 1 & 2500 & 66 & 4 \\
\hline
\end{tabular}




\begin{tabular}{|c|c|c|c|c|}
\hline OBS. NO. & BEST MODEL & PRICE & SCORE & QUALITY \\
\hline 16 & 1 & 2500 & 66 & 4 \\
\hline 97 & 1 & 2500 & 66 & 4 \\
\hline 139 & 1 & 2500 & 66 & 4 \\
\hline 3 & 1 & 2500 & 69 & 4 \\
\hline 13 & 1 & 2500 & 69 & 4 \\
\hline 15 & 1 & 2500 & 69 & 4 \\
\hline 66 & 1 & 2500 & 69 & 4 \\
\hline 96 & 1 & 2500 & 69 & 4 \\
\hline 108 & 1 & 2500 & 69 & 4 \\
\hline 145 & 1 & 2500 & 69 & 4 \\
\hline 151 & 1 & 2500 & 69 & 4 \\
\hline 153 & 1 & 2500 & 69 & 4 \\
\hline 19 & 1 & 2500 & 72 & 4 \\
\hline 21 & 1 & 2500 & 72 & 4 \\
\hline 25 & 1 & 2500 & 72 & 4 \\
\hline 34 & 1 & 2500 & 72 & 4 \\
\hline 72 & 1 & 2500 & 72 & 4 \\
\hline 105 & 1 & 2500 & 72 & 4 \\
\hline 144 & 1 & 2500 & 72 & 4 \\
\hline 146 & 1 & 2500 & 72 & 4 \\
\hline 75 & 1 & 2500 & 76 & 4 \\
\hline 88 & 1 & 2500 & 76 & 4 \\
\hline 111 & 1 & 2500 & 76 & 4 \\
\hline 138 & 1 & 2500 & 76 & 4 \\
\hline 20 & 1 & 2500 & 79 & 4 \\
\hline 52 & 1 & 2500 & 79 & 4 \\
\hline 61 & 1 & 2500 & 79 & 4 \\
\hline 103 & 1 & 2500 & 79 & 4 \\
\hline 46 & 1 & 2500 & 83 & 4 \\
\hline 50 & 1 & 2500 & 83 & 4 \\
\hline 85 & 1 & 2500 & 83 & 4 \\
\hline 89 & 1 & 2500 & 83 & 4 \\
\hline 95 & 1 & 2500 & 83 & 4 \\
\hline 142 & 1 & 2500 & 83 & 4 \\
\hline 7 & 1 & 2500 & 86 & 4 \\
\hline 12 & 1 & 2500 & 86 & 4 \\
\hline 62 & 1 & 2500 & 86 & 4 \\
\hline 68 & 1 & 2500 & 86 & 4 \\
\hline 100 & 1 & 2500 & 86 & 4 \\
\hline 17 & 1 & 2500 & 90 & 4 \\
\hline 30 & 1 & 2500 & 90 & 4 \\
\hline 53 & 1 & 2500 & 90 & 4 \\
\hline 101 & 1 & 2500 & 90 & 4 \\
\hline 136 & 1 & 2500 & 90 & 4 \\
\hline 148 & 1 & 2500 & 90 & 4 \\
\hline 150 & 1 & 2500 & 90 & 4 \\
\hline
\end{tabular}




\begin{tabular}{ccccc}
\hline OBS. NO. & BEST MODEL & PRICE & SCORE & QUALITY \\
\hline 32 & 1 & 2500 & 93 & 4 \\
104 & 1 & 2500 & 93 & 4 \\
22 & 1 & 2500 & 97 & 4 \\
152 & 1 & 2500 & 100 & 4 \\
4 & 4 & 2600 & 24 & 1 \\
29 & 4 & 2600 & 62 & 1 \\
110 & 4 & 2600 & 62 & 1 \\
60 & 4 & 2600 & 66 & 1 \\
63 & 4 & 2600 & 83 & 1 \\
141 & 3 & 2800 & 41 & 3 \\
37 & 3 & 2800 & 52 & 3 \\
102 & 3 & 2800 & 52 & 3 \\
92 & 3 & 2800 & 59 & 3 \\
51 & 3 & 2800 & 69 & 3 \\
24 & 3 & 2800 & 79 & 3 \\
45 & 3 & 2800 & 83 & 3 \\
31 & 3 & 2800 & 93 & 3 \\
\hline
\end{tabular}




\section{Appendix D}

Observations: Technical Attributes vs. Price-Perceived Quality 


\begin{tabular}{|c|c|c|c|c|c|c|c|c|}
\hline $\begin{array}{l}\text { OBSERVATION } \\
\text { NUMBER }\end{array}$ & $\begin{array}{c}\text { BEST } \\
\text { MODEL }\end{array}$ & PRICE & $\begin{array}{c}\text { PROCESSING } \\
\text { SPEED }\end{array}$ & $\begin{array}{l}\text { RAM } \\
\text { SIZE }\end{array}$ & $\begin{array}{l}\text { HARD DRIVE } \\
\text { SIZE }\end{array}$ & $\begin{array}{l}\text { CD-ROM } \\
\text { SPEED }\end{array}$ & SCORES & QUALITY \\
\hline 5 & 2 & 2400 & 66 & 8 & 340 & 300 & 34 & 2 \\
\hline 56 & 2 & 2400 & 66 & 8 & 340 & 300 & 34 & 2 \\
\hline 57 & 2 & 2400 & 66 & 8 & 340 & 300 & 41 & 2 \\
\hline 9 & 2 & 2400 & 66 & 8 & 340 & 300 & 45 & 2 \\
\hline 1 & 2 & 2400 & 66 & 8 & 340 & 300 & 52 & 2 \\
\hline 125 & 2 & 2400 & 66 & 8 & 340 & 300 & 52 & 2 \\
\hline 35 & 2 & 2400 & 66 & 8 & 340 & 300 & 55 & 2 \\
\hline 36 & 2 & 2400 & 66 & 8 & 340 & 300 & 59 & 2 \\
\hline 133 & 2 & 2400 & 66 & 8 & 340 & 300 & 59 & 2 \\
\hline 143 & 2 & 2400 & 66 & 8 & 340 & 300 & 59 & 2 \\
\hline 149 & 2 & 2400 & 66 & 8 & 340 & 300 & 59 & 2 \\
\hline 26 & 2 & 2400 & 66 & 8 & 340 & 300 & 62 & 2 \\
\hline 59 & 2 & 2400 & 66 & 8 & 340 & 300 & 62 & 2 \\
\hline 28 & 2 & 2400 & 66 & 8 & 340 & 300 & 66 & 2 \\
\hline 74 & 2 & 2400 & 66 & 8 & 340 & 300 & 66 & 2 \\
\hline 98 & 2 & 2400 & 66 & 8 & 340 & 300 & 69 & 2 \\
\hline 134 & 2 & 2400 & 66 & 8 & 340 & 300 & 76 & 2 \\
\hline 54 & 2 & 2400 & 66 & 8 & 340 & 300 & 79 & 2 \\
\hline 70 & 2 & 2400 & 66 & 8 & 340 & 300 & 79 & 2 \\
\hline 71 & 2 & 2400 & 66 & 8 & 340 & 300 & 79 & 2 \\
\hline 42 & 2 & 2400 & 66 & 8 & 340 & 300 & 83 & 2 \\
\hline 112 & 1 & 2500 & 66 & 8 & 426 & 350 & 41 & 4 \\
\hline 8 & 1 & 2500 & 66 & 8 & 426 & 350 & 45 & 4 \\
\hline 67 & 1 & 2500 & 66 & 8 & 426 & 350 & 45 & 4 \\
\hline 27 & 1 & 2500 & 66 & 8 & 426 & 350 & 48 & 4 \\
\hline 14 & 1 & 2500 & 66 & 8 & 426 & 350 & 52 & 4 \\
\hline 64 & 1 & 2500 & 66 & 8 & 426 & 350 & 52 & 4 \\
\hline 76 & 1 & 2500 & 66 & 8 & 426 & 350 & 52 & 4 \\
\hline 90 & 1 & 2500 & 66 & 8 & 426 & 350 & 52 & 4 \\
\hline 123 & 1 & 2500 & 66 & 8 & 426 & 350 & 52 & 4 \\
\hline 65 & 1 & 2500 & 66 & 8 & 426 & 350 & 55 & 4 \\
\hline 73 & 1 & 2500 & 66 & 8 & 426 & 350 & 55 & 4 \\
\hline 87 & 1 & 2500 & 66 & 8 & 426 & 350 & 55 & 4 \\
\hline 94 & 1 & 2500 & 66 & 8 & 426 & 350 & 55 & 4 \\
\hline 2 & 1 & 2500 & 66 & 8 & 426 & 350 & 59 & 4 \\
\hline 58 & 1 & 2500 & 66 & 8 & 426 & 350 & 59 & 4 \\
\hline 69 & 1 & 2500 & 66 & 8 & 426 & 350 & 59 & 4 \\
\hline 18 & 1 & 2500 & 66 & 8 & 426 & 350 & 62 & 4 \\
\hline 23 & 1 & 2500 & 66 & 8 & 426 & 350 & 62 & 4 \\
\hline 33 & 1 & 2500 & 66 & 8 & 426 & 350 & 62 & 4 \\
\hline 140 & 1 & 2500 & 66 & 8 & 426 & 350 & 62 & 4 \\
\hline 6 & 1 & 2500 & 66 & 8 & 426 & 350 & 66 & 4 \\
\hline 10 & 1 & 2500 & 66 & 8 & 426 & 350 & 66 & 4 \\
\hline 16 & 1 & 2500 & 66 & 8 & 426 & 350 & 66 & 4 \\
\hline
\end{tabular}




\begin{tabular}{|c|c|c|c|c|c|c|c|c|}
\hline $\begin{array}{l}\text { OBSERVATION } \\
\text { NUMBER }\end{array}$ & $\begin{array}{c}\text { BEST } \\
\text { MODEL }\end{array}$ & PRICE & $\begin{array}{l}\text { PROCESSING } \\
\text { SPEED }\end{array}$ & $\begin{array}{l}\text { RAM } \\
\text { SIZE }\end{array}$ & $\begin{array}{l}\text { HARD DRIVE } \\
\text { SIZE }\end{array}$ & $\begin{array}{l}\text { CD-ROM } \\
\text { SPEED }\end{array}$ & SCORES & QUALITY \\
\hline 97 & 1 & 2500 & 66 & 8 & 426 & 350 & 66 & 4 \\
\hline 139 & 1 & 2500 & 66 & 8 & 426 & 350 & 66 & 4 \\
\hline 3 & 1 & 2500 & 66 & 8 & 426 & 350 & 69 & 4 \\
\hline 13 & 1 & 2500 & 66 & 8 & 426 & 350 & 69 & 4 \\
\hline 15 & 1 & 2500 & 66 & 8 & 426 & 350 & 69 & 4 \\
\hline 66 & 1 & 2500 & 66 & 8 & 426 & 350 & 69 & 4 \\
\hline 96 & 1 & 2500 & 66 & 8 & 426 & 350 & 69 & 4 \\
\hline 108 & 1 & 2500 & 66 & 8 & 426 & 350 & 69 & 4 \\
\hline 145 & 1 & 2500 & 66 & 8 & 426 & 350 & 69 & 4 \\
\hline 151 & 1 & 2500 & 66 & 8 & 426 & 350 & 69 & 4 \\
\hline 153 & 1 & 2500 & 66 & 8 & 426 & 350 & 69 & 4 \\
\hline 19 & 1 & 2500 & 66 & 8 & 426 & 350 & 72 & 4 \\
\hline 21 & 1 & 2500 & 66 & 8 & 426 & 350 & 72 & 4 \\
\hline 25 & 1 & 2500 & 66 & 8 & 426 & 350 & 72 & 4 \\
\hline 34 & 1 & 2500 & 66 & 8 & 426 & 350 & 72 & 4 \\
\hline 72 & 1 & 2500 & 66 & 8 & 426 & 350 & 72 & 4 \\
\hline 105 & 1 & 2500 & 66 & 8 & 426 & 350 & 72 & 4 \\
\hline 144 & 1 & 2500 & 66 & 8 & 426 & 350 & 72 & 4 \\
\hline 146 & 1 & 2500 & 66 & 8 & 426 & 350 & 72 & 4 \\
\hline 75 & 1 & 2500 & 66 & 8 & 426 & 350 & 76 & 4 \\
\hline 88 & 1 & 2500 & 66 & 8 & 426 & 350 & 76 & 4 \\
\hline 111 & 1 & 2500 & 66 & 8 & 426 & 350 & 76 & 4 \\
\hline 138 & 1 & 2500 & 66 & 8 & 426 & 350 & 76 & 4 \\
\hline 20 & 1 & 2500 & 66 & 8 & 426 & 350 & 79 & 4 \\
\hline 52 & 1 & 2500 & 66 & 8 & 426 & 350 & 79 & 4 \\
\hline 61 & 1 & 2500 & 66 & 8 & 426 & 350 & 79 & 4 \\
\hline 103 & 1 & 2500 & 66 & 8 & 426 & 350 & 79 & 4 \\
\hline 46 & 1 & 2500 & 66 & 8 & 426 & 350 & 83 & 4 \\
\hline 50 & 1 & 2500 & 66 & 8 & 426 & 350 & 83 & 4 \\
\hline 85 & 1 & 2500 & 66 & 8 & 426 & 350 & 83 & 4 \\
\hline 89 & 1 & 2500 & 66 & 8 & 426 & 350 & 83 & 4 \\
\hline 95 & 1 & 2500 & 66 & 8 & 426 & 350 & 83 & 4 \\
\hline 142 & 1 & 2500 & 66 & 8 & 426 & 350 & 83 & 4 \\
\hline 7 & 1 & 2500 & 66 & 8 & 426 & 350 & 86 & 4 \\
\hline 12 & 1 & 2500 & 66 & 8 & 426 & 350 & 86 & 4 \\
\hline 62 & 1 & 2500 & 66 & 8 & 426 & 350 & 86 & 4 \\
\hline 68 & 1 & 2500 & 66 & 8 & 426 & 350 & 86 & 4 \\
\hline 100 & 1 & 2500 & 66 & 8 & 426 & 350 & 86 & 4 \\
\hline 17 & 1 & 2500 & 66 & 8 & 426 & 350 & 90 & 4 \\
\hline 30 & 1 & 2500 & 66 & 8 & 426 & 350 & 90 & 4 \\
\hline 53 & 1 & 2500 & 66 & 8 & 426 & 350 & 90 & 4 \\
\hline 101 & 1 & 2500 & 66 & 8 & 426 & 350 & 90 & 4 \\
\hline 136 & 1 & 2500 & 66 & 8 & 426 & 350 & 90 & 4 \\
\hline
\end{tabular}




\begin{tabular}{|c|c|c|c|c|c|c|c|c|}
\hline $\begin{array}{c}\text { OBSERVATION } \\
\text { NUMBER }\end{array}$ & $\begin{array}{c}\text { BEST } \\
\text { MODEL }\end{array}$ & PRICE & $\begin{array}{l}\text { PROCESSING } \\
\text { SPEED }\end{array}$ & $\begin{array}{l}\text { RAM } \\
\text { SIZE }\end{array}$ & $\begin{array}{l}\text { HARD DRIVE } \\
\text { SIZE }\end{array}$ & $\begin{array}{l}\text { CD-ROM } \\
\text { SPEED }\end{array}$ & SCORES & QUALITY \\
\hline 148 & 1 & 2500 & 66 & 8 & 426 & 350 & 90 & 4 \\
\hline 150 & 1 & 2500 & 66 & 8 & 426 & 350 & 90 & 4 \\
\hline 32 & 1 & 2500 & 66 & 8 & 426 & 350 & 93 & 4 \\
\hline 104 & 1 & 2500 & 66 & 8 & 426 & 350 & 93 & 4 \\
\hline 22 & 1 & 2500 & 66 & 8 & 426 & 350 & 97 & 4 \\
\hline 152 & 1 & 2500 & 66 & 8 & 426 & 350 & 100 & 4 \\
\hline 4 & 4 & 2600 & 33 & 4 & 210 & 300 & 24 & 1 \\
\hline 29 & 4 & 2600 & 33 & 4 & 210 & 300 & 62 & 1 \\
\hline 110 & 4 & 2600 & 33 & 4 & 210 & 300 & 62 & 1 \\
\hline 60 & 4 & 2600 & 33 & 4 & 210 & 300 & 66 & 1 \\
\hline 63 & 4 & 2600 & 33 & 4 & 210 & 300 & 83 & 1 \\
\hline 141 & 3 & 2800 & 66 & 8 & 340 & 300 & 41 & 3 \\
\hline 37 & 3 & 2800 & 66 & 8 & 340 & 300 & 52 & 3 \\
\hline 102 & 3 & 2800 & 66 & 8 & 340 & 300 & 52 & 3 \\
\hline 92 & 3 & 2800 & 66 & 8 & 340 & 300 & 59 & 3 \\
\hline 51 & 3 & 2800 & 66 & 8 & 340 & 300 & 69 & 3 \\
\hline 24 & 3 & 2800 & 66 & 8 & 340 & 300 & 79 & 3 \\
\hline 45 & 3 & 2800 & 66 & 8 & 340 & 300 & 83 & 3 \\
\hline 31 & 3 & 2800 & 66 & 8 & 340 & 300 & 93 & 3 \\
\hline
\end{tabular}

